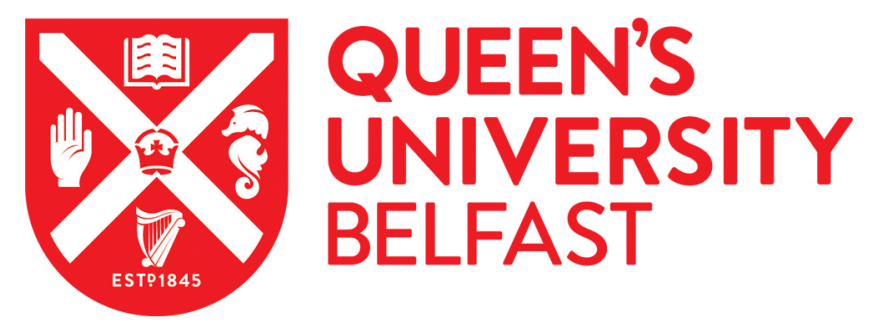

\title{
Performance Characterisation of a Range of Diesel Oxidation Catalysts: Effect of Pt:Pd Ratio on Light Off Behaviour and Nitrogen Species Formation
}

Glover, L., Douglas, R., \& McCullough, G. (2011). Performance Characterisation of a Range of Diesel Oxidation Catalysts: Effect of Pt:Pd Ratio on Light Off Behaviour and Nitrogen Species Formation. Paper presented at 10th International Conference on Engines and Vehicles, Capri, Naples, Italy.

Queen's University Belfast - Research Portal:

Link to publication record in Queen's University Belfast Research Portal

\section{General rights}

Copyright for the publications made accessible via the Queen's University Belfast Research Portal is retained by the author(s) and / or other copyright owners and it is a condition of accessing these publications that users recognise and abide by the legal requirements associated with these rights.

Take down policy

The Research Portal is Queen's institutional repository that provides access to Queen's research output. Every effort has been made to ensure that content in the Research Portal does not infringe any person's rights, or applicable UK laws. If you discover content in the Research Portal that you believe breaches copyright or violates any law, please contact openaccess@qub.ac.uk. 


\title{
The Effect of De-Greening and Pre-Treatment on Automotive Catalyst Performance
}

\author{
Claire McAtee, Geoffrey McCullough, Roy Douglas and Laura Glover \\ Queen's University Belfast
}

Copyright (C) 2011 SAE International

doi: $10.4271 / 2011-24-0188$

\begin{abstract}
Computer simulation is now considered to be a crucial stage in the design of automotive catalysts due to the increasing complexity of modern aftertreatment systems. The resulting models almost invariably include surface reaction kinetics that are measured under controlled conditions similar to those found on a vehicle. Repeatability of the measurements used to infer surface reaction rates is fundamental to the accuracy of the resulting catalyst model. To achieve the required level of repeatability it is necessary to ensure that the catalyst sample in question is stable and that its activity does not change during the test phase. It is therefore essential that the catalyst has been lightly aged, or 'de-greened' before testing begins. It is also known that the state of the catalyst's surface prior to testing has an impact on its subsequent light-off performance and that test history can play an important role in catalyst activity. Suitably pre-treating the catalyst surface can ensure that a reference point is reached prior to a light-off test. The work summarised in this paper includes a study of both the de-greening phase and the state of the catalyst's surface on its activity, with the aim of developing a robust test protocol that provides repeatable kinetic data under realistic operating conditions.
\end{abstract}

To establish a protocol for initial stabilisation of new catalyst samples a series of tests were conducted on catalysts that had been thermally aged at $600^{\circ} \mathrm{C}$ and $750^{\circ} \mathrm{C}$ respectively until the sample exhibited stability. The activity of the sample was assessed by repeating identical CO light-off tests following each period of time in the oven. A period of 8 hours at $750^{\circ} \mathrm{C}$ was found to sufficiently stabilise the sample.

In the pre-treatment study an investigation into the effect of several pre-treatment protocols on CO light off was carried out on a three-way catalyst of commercial formulation in order to establish a robust protocol to ensure test repeatability. The investigation focused on pre-treating the catalyst sample in hydrogen, oxygen or nitrogen environments at specified conditions of flow and temperature. Following pre-treatment, identical CO light-off tests were performed in order to assess the respective influences of each pre-treatment. A trend of lower light off temperatures was observed for all pre-treatment strategies on the first of two consecutive light-off temperature ramps with a notable increase in light off temperature observed on the second ramp. As a result of this study a pre-treatment protocol was established. The protocol involves treating the catalyst sample in flowing nitrogen up to $600^{\circ} \mathrm{C}$ using a temperature ramp of $15^{\circ} \mathrm{C} / \mathrm{min}$.

\section{INTRODUCTION}

The generation of toxic and pollutant emissions such as $\mathrm{CO}$, $\mathrm{HCs}$ and $\mathrm{NO}_{\mathrm{x}}$ from mobile vehicles as a result of burning fossil fuels is a topic that has received a considerable amount of attention for more than four decades. As the volume of mobile vehicles continues to increase the emissions legislation imposed on such vehicles has become progressively more stringent. Although the emissions generated can be mitigated to an extent by engine management strategies, these are not sufficient to meet the laws imposed by legislators. To achieve the required tail-pipe emissions a catalytic converter is an essential device.

The automotive catalytic converter is typically a ceramic monolith structure specifically designed to convert toxic and pollutant emissions resulting from incomplete combustion within the engine. The device achieves this by using precious metals (PMs) such as Pt, Pd and Rh to oxidise or reduce the respective compounds. The selection of the PMs used and any additional chemical compounds is entirely dependent on the gaseous atmosphere within which the converter will be 
required to operate i.e. stoichiometric (gasoline) or lean (diesel or gasoline lean burn) conditions and as a result the chemical compounds to which the converter will be subjected.

The ideal conversion pathways for the main pollutants, $\mathrm{CO}$, $\mathrm{HCs}$ and $\mathrm{NO}_{\mathrm{x}}$ to be eliminated are detailed in Equations 1, $\underline{2}$, $\underline{3}, \underline{4}, \underline{5}$ where Equations 1 and $\underline{2}$ are oxidation reactions and Equations $3, \underline{4}, \underline{5}$ represent reduction reactions [1].

$$
\begin{gathered}
2 \mathrm{CO}+\mathrm{O}_{2} \rightarrow \mathrm{CO}_{2} \\
\mathrm{HC}+\mathrm{O}_{2} \rightarrow \mathrm{CO}_{2}+\mathrm{H}_{2} \mathrm{O} \\
2 \mathrm{CO}+2 \mathrm{NO} \rightarrow 2 \mathrm{CO}_{2}+\mathrm{N}_{2} \\
\mathrm{HC}+\mathrm{NO} \rightarrow \mathrm{CO}_{2}+\mathrm{H}_{2} \mathrm{O}+\mathrm{N}_{2} \\
2 \mathrm{H}_{2}+2 \mathrm{NO} \rightarrow 2 \mathrm{H}_{2} \mathrm{O}+\mathrm{N}_{2}
\end{gathered}
$$

These equations represent the most straight forward pathways to the desired end products of $\mathrm{CO}_{2}, \mathrm{H}_{2} \mathrm{O}$ and $\mathrm{N}_{2}$. However, in reality there are many possible intermediates within these reactions which may produce various $\mathrm{HCs}$ and other undesired products [2]].

It is important that the catalytic converter work as efficiently as possible with respect to conversion of the harmful pollutants in question. The most notable drawback of the catalytic converter is that it will only convert the toxins when it has reached its operating temperature. The activity of a catalytic converter is typically described by measuring its conversion efficiency relative to its feed gas temperature; this is widely referred to as its light-off. The light-off temperature is defined as the temperature at which the catalytic converter converts $50 \%\left(\mathrm{~T}_{50}\right)$ of the inlet concentration of the toxin in question.

Catalyst performance is often assessed using engine tests whereby the exhaust gas emissions are analysed directly from the engine post catalyst. These tests incorporate various strategies to assess catalyst performance during different modes of operation such as cold start and transient operation $[\underline{3}, \underline{4}, \underline{5}]$. In addition to engine testing chassis dynamometer tests are used to ensure that vehicle fleets meet the relevant emission regulation requirements by using simulated drive cycles [ $\underline{6}-7]$. Although engine and dynamometer tests are useful for proving that after-treatment systems adequately meet the required standard for on-road use, the extraction of reaction rates and kinetics from such tests is not feasible. In order to establish kinetic equations a high degree of repeatability is critical as well as the ability to vary individual gas component concentrations to allow assessment of inhibiting or promoting characteristics. One method of achieving this repeatability and independent control of individual gas components is simulation of exhaust gas mixtures. This can be achieved by using a mixture of synthetic gases representative of a real exhaust gas stream by employing mass flow controllers and a controllable furnace to achieve a representative heating pattern. This approach is particularly useful when investigating in detail the chemical kinetics and light-off characteristics of a particular catalyst sample [ㅁ-ㅁ].

The measurement of kinetics is essential for modelling the behaviour of automotive catalysts. Experimental testing of commercial automotive catalysts in a controlled environment which allows variation of specific gas concentrations and temperature conditions facilitates the calculation of reaction rates and kinetics. By observing how one gas specie within a mixture affects the reaction rate of itself and other species gives an insight into the inhibiting or promoting effects of the respective gas within a mixture. Use of a synthetic gas reactor allows for such variation of concentrations which would not be possible on an engine. The oxidation of carbon monoxide is one example where the ability to vary gas concentration is an advantage as it is well known that carbon monoxide inhibits its own oxidation. Increasing concentrations of oxygen promotes the reaction rate while the presence of hydrocarbons and $\mathrm{NO}_{\mathrm{x}}$ also inhibit this particular reaction. The resulting surface reaction expression is essential for modelling the behaviour of $\mathrm{CO}$ such as that detailed in Equation 6 which incorporates inhibiting and promoting terms with respect to the oxidation of CO [9]. Measurement of reaction kinetics is therefore required for individual gas species within a representative exhaust gas mixture in order to build robust catalyst simulation models.

$$
r_{c o}=\frac{-k_{r 1}(\mathrm{CO})\left(\mathrm{O}_{2}\right)}{\left[1+k_{a 1}\left[(\mathrm{CO})+k_{a 2}\left(\mathrm{C}_{3} \mathrm{H}_{6}\right)\right]^{2} \times\right.} \quad \text { mol CO } / \mathrm{m}^{2} P M
$$

There are further factors which affect repeatability in catalyst testing. When a catalyst sample is new, also referred to as being 'green', it is necessary to stabilise the sample [10-11]. The activity of a catalyst sample rapidly reduces during the first few hours of use due to sintering of the surface as a result of exposure to high temperatures. Agglomeration of the precious metal particles reduces the availability of the active phase for reaction. The stability of the catalyst sample used to build kinetics is critical and so it is important to ensure that the surface of the sample is sufficiently stable. Therefore, it is common practice to 'de-green' a new catalyst sample to ensure that it is stable prior to the commencement of its test 
life and to ensure repeatable and reliable results. The extraction of kinetics from a fresh catalyst would be meaningless as any results would be unrepresentative of the typical conditions experienced on a vehicle as the green catalyst would exhibit increased activity and would also experience a continual change in its surface state. As a result of the requirement for surface stability, the aim of this study was to establish a robust procedure for de-greening by subjecting a catalyst sample to cumulative periods of time in air at high temperatures and testing the sample's activity using a CO light-off at each interval until the sample exhibited repeatable results.

In addition to the de-greening study presented, a further investigation into pre-treatment of the catalyst sample is also included $[\underline{10}][\underline{12}, \underline{13}, \underline{14}, \underline{15}]$. The state of catalyst sample surface is a further factor which influences catalytic activity and so affects the subsequent kinetics extracted from empirical results. Therefore it is necessary to work from a datum point where the sample surface is in a similar state prior to each test. This study focuses on the effect of a reducing, oxidising or inert pre-treatment strategy on the surface of the catalyst and the subsequent effect on the activity of the sample by using a CO light-off. The objective of this study was to ascertain whether it is necessary to periodically 'clean' the catalyst surface to ensure that it remains in a consistent state for each of the tests to which it is subjected.

\section{EXPERIMENTAL}

This study was conducted using the SIGU 2000 simulated gas generator manufactured by Horiba. This instrument incorporates mass flow controllers (MFCs) which are connected to synthetic gas bottles via stainless steel gas lines. There are nineteen MFCs including one liquid MFC for injection of water into the mixture and three for perturbation. The system also incorporates two liquid hydrocarbon baths which can be used for injection of hydrocarbons such as decane, toluene, xylene and ethanol. The MFCs have an accuracy of $+/-1 \%$, repeatability of $+/-0.2 \%$ and stability of $+/-1 \%$ /hour. All synthetic gases were supplied by BOC. The mass flow controllers ensure the desired gas concentrations are transported through to the catalyst sample which is located within the instrument. An integrated furnace allows the user to specify the desired temperature profile for control of catalyst inlet temperature; the temperature can be increased at rates up to $50^{\circ} \mathrm{C} / \mathrm{min}$. The gas mixture passes through the catalyst sample and is then transported through a heated line from the SIGU to a splitter box. The splitter box can split the flow from the SIGU into three further heated lines allowing up to three analysers to be used for gas sample analysis.

The analysers used in this study were a Horiba 6000FT (FTIR) and a Horiba MEXA 7170 exhaust gas analyser. The FTIR is capable of speciating twenty-four chemical compounds while the MEXA measures $\mathrm{CO}, \mathrm{CO}_{2}, \mathrm{O}_{2}$, Total Hydrocarbons, $\mathrm{NO}_{\mathrm{x}}$ and $\mathrm{SO}_{2}$. A schematic of the laboratory can be seen in Figure 1 where the arrows represent the direction of gas flow.

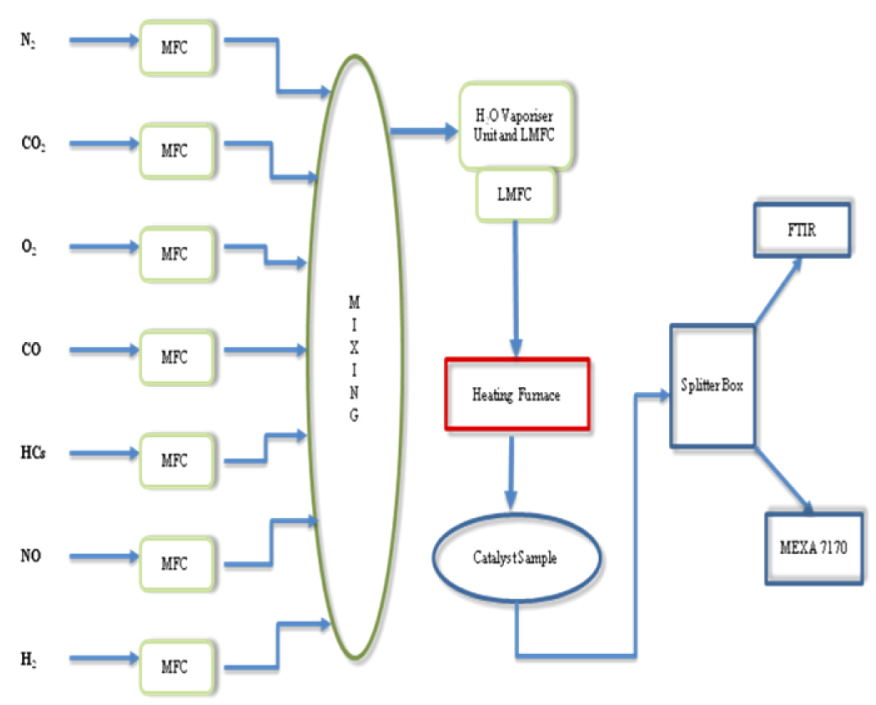

Figure 1. Laboratory Schematic

The FTIR data is logged at $1 \mathrm{~Hz}$ while the MEXA readings are recorded using a separate $\mathrm{PC}$ at a rate of $5 \mathrm{~Hz}$. The catalyst inlet and outlet temperatures are also logged once every five seconds. As the concentration of gas entering the catalyst is known and the outlet concentration is given by the analysers the conversion efficiency can be calculated using Equation 7.

$$
\begin{aligned}
& \text { Conversion Efficiency }(\%)= \\
& \frac{\lfloor\text { Concentration }\rfloor_{\text {in }}-\lfloor\text { Concentration }\rfloor_{\text {out }}}{[\text { Concentration }]_{\text {in }}} \times 100
\end{aligned}
$$

The test sample used in this study was a three-way catalyst (TWC) of commercial formulation with $\mathrm{Pd}$ and $\mathrm{Rh}$ as the active metals in a ratio of $5: 1$ with a loading of $1.8 \mathrm{~g} / \mathrm{L}(50 \mathrm{~g} /$ $\mathrm{ft}^{3}$ ). The catalyst was received as a full brick and cored to diameters of $30 \mathrm{~mm}$. The flow rate for CO light-off tests was calculated based on catalyst volume to give a space velocity of $50,000 \mathrm{~h}^{-1}$. Test results from three samples are presented for the respective de-greening and pre-treatment studies. 'Sample 1' was used initially in the de-greening study and also in the subsequent pre-treatment study. 'Sample 2' was used in the de-greening study only and 'Sample 3' was used in the pre-treatment study only. 
The light-off test procedure incorporated a warm up ramp in $\mathrm{N}_{2}$ only with a temperature profile of $20^{\circ} \mathrm{C} / \mathrm{min}$ to $300^{\circ} \mathrm{C}$ followed by a cool down to $80^{\circ} \mathrm{C}$. The purpose of the warm up ramp was to ensure that the sample had a uniform temperature throughout i.e. the catalyst inlet and outlet temperature readings were equal. Following the warm up the $\mathrm{CO}$ and $\mathrm{O}_{2}$ mass flow controllers were switched on and delivered concentrations of 0.5 and $2 \%$ respectively. Following the injection of the reactant gases the first of two consecutive light-off temperature ramps was initiated. The light-off test temperature profile incorporated a temperature increase rate of $5^{\circ} \mathrm{C} / \mathrm{min}$ up to an inlet temperature of $300^{\circ} \mathrm{C}$ followed by a cool down to $80^{\circ} \mathrm{C}$ where the catalyst inlet and outlet temperatures were again allowed to stabilise before a second identical light-off temperature ramp began. Figure 2 shows an example of the temperature ramp profile used; the first of the three peaks is the warm-up ramp followed by two consecutive light-off temperature ramps. This procedure was employed as the warm up ensured uniform sample temperature and the two light-off temperature ramps to $300^{\circ} \mathrm{C}$ were sufficient to achieve maximum conversion efficiency. Figure 3 shows two light-off curves from separate tests which used the same catalyst and the same gas composition; these curves illustrate the excellent repeatability from this system. For example, the light-off temperature is repeatable to within $0.5^{\circ} \mathrm{C}$.

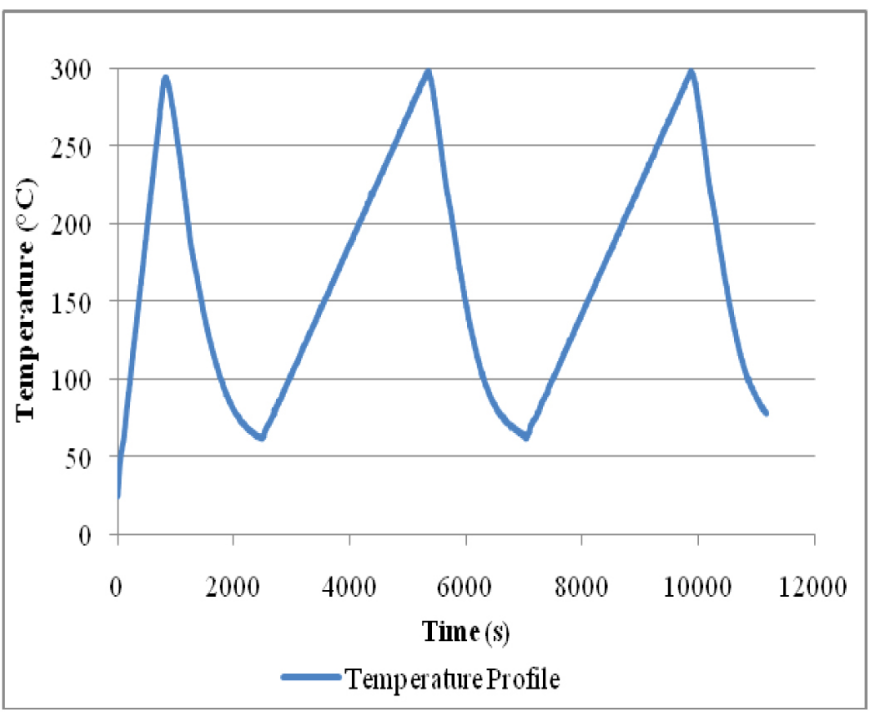

Figure 2. Temperature Profile used for CO Light-Off Test

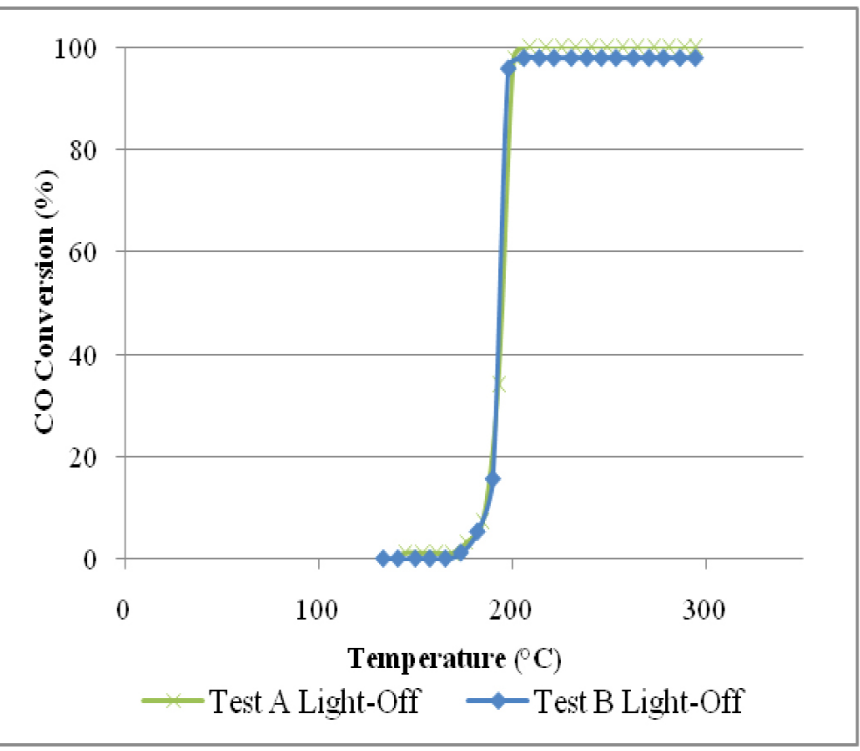

Figure 3. Light-Off Curves obtained from Separate Tests on the Experimental Equipment

\section{RESULTS AND DISCUSSION DE-GREENING STUDY}

The procedure used in the de-greening study involved a 'green' CO light-off test on Sample 1 and subsequent CO light-off tests following each consecutive period of time in the oven. Initially an oven temperature of $600^{\circ} \mathrm{C}$ was used until a cumulative total of 8 hours was reached; as stabilisation was not yet evident the temperature was increased to $750^{\circ} \mathrm{C}$. The oven was brought to temperature and the sample was then placed in the oven for the specified period of time. The oven was then allowed to cool before removing the sample.

Following each stint in the oven a treatment in $3 \% \mathrm{H}_{2}$ was performed; this was carried out at a space velocity of 25,000 $\mathrm{h}^{-1}$ up to $400^{\circ} \mathrm{C}$ at which point the temperature was held for 10 minutes followed by a further ramp to $500^{\circ} \mathrm{C}[\underline{12}]$. This was followed by a treatment in $5 \% \mathrm{O}_{2}$ at a space velocity of $50,000 \mathrm{~h}^{-1}$ at $192^{\circ} \mathrm{C}$ for 30 minutes [13]. Following these treatments a CO light-off test was performed. The motivation for these treatments was to ensure that the catalyst sample was being tested from a datum point after each period of time in the oven thereby ensuring that the only variable was the duration it had spent in the oven. A space velocity of 25,000 $\mathrm{h}^{-1}$ was used for the $\mathrm{H}_{2}$ due to a limitation with the mass flow controller total flow. In order to achieve a higher $\mathrm{H}_{2}$ concentration the total flow was reduced and as a consequence the space velocity was reduced. Table 1 details the concentrations for the $\mathrm{H}_{2}, \mathrm{O}_{2}$ and $\mathrm{CO}$ light-off procedures. 
Table 1. Gas Compositions for Hydrogen Reduction, Oxidation and CO Light-Off

\begin{tabular}{|c|c|c|}
\hline & $\begin{array}{c}\text { Gas } \\
\text { Composition }\end{array}$ & $\begin{array}{c}\text { Space } \\
\text { Velocity }\left(\mathbf{h}^{-\mathbf{1}}\right)\end{array}$ \\
\hline $\begin{array}{c}\text { Hydrogen } \\
\text { Reduction }\end{array}$ & $\begin{array}{c}3 \% \mathrm{H}_{2} \\
\text { Balance in } \mathrm{N}_{2}\end{array}$ & 25,000 \\
\hline Oxidation & $\begin{array}{c}5 \% \mathrm{O}_{2} \\
\text { Balance in } \mathrm{N}_{2}\end{array}$ & 50,000 \\
\hline CO Light-Off & $\begin{array}{c}0.5 \% \mathrm{CO} \\
2 \% \mathrm{O}_{2} \\
\text { Balance in } \mathrm{N}_{2}\end{array}$ & 50,000 \\
\hline
\end{tabular}

The cumulative total time spent in the oven along with the corresponding CO light-off test number is detailed in Table 2.

Table 2. Cumulative De-greening Details of Sample 1

\begin{tabular}{|c|c|c|c|}
\hline $\begin{array}{c}\text { Light- } \\
\text { Off Test } \\
\text { Number }\end{array}$ & $\begin{array}{c}\text { Cumulative } \\
\text { Hours at } \\
\mathbf{6 0 0}^{\circ} \mathbf{C}\end{array}$ & $\begin{array}{c}\text { Cumulative } \\
\text { Hours at } \\
\mathbf{7 5 0}^{\circ} \mathbf{C}\end{array}$ & $\begin{array}{c}\text { Total } \\
\text { Hours in } \\
\text { Oven }\end{array}$ \\
\hline 1 & 0 & 0 & 0 \\
\hline 2 & 0 & 0 & 0 \\
\hline 3 & 4 & 0 & 4 \\
\hline 4 & 5 & 0 & 5 \\
\hline 5 & 8 & 0 & 8 \\
\hline 6 & 8 & 1 & 9 \\
\hline 7 & 8 & 3 & 11 \\
\hline 8 & 8 & 8 & 16 \\
\hline
\end{tabular}

Tests 1 and 2 were performed before Sample 1 had been subjected to any de-greening in the oven; as the sample was completely green before these set of tests were undertaken it was of interest to observe the effect of performance testing alone before de-greening in the oven commenced. In conjunction with Table 2 the light-off curves associated with each of the tests are illustrated in Figures 4 and $\underline{5}$ (tests numbered 1-8 to co-ordinate with Table 2). It is important to note that Figure 4 shows the conversion curves from the first of the two consecutive temperature ramps which are included in each light-off test while Figure 5 shows the conversion curves for the second of the two ramps. The reason for using this particular depiction of the tests was due to the fact that very early conversion of $\mathrm{CO}$ was observed upon injection of the reactant gases $\left(\mathrm{CO}\right.$ and $\left.\mathrm{O}_{2}\right)$ following the warm up in $\mathrm{N}_{2}$. This phenomenon is thought to be a result of the pretreatment the sample received using hydrogen and oxygen directly prior to each CO light-off activity test. This effect is discussed further in the pre-treatment study presented later in this document.

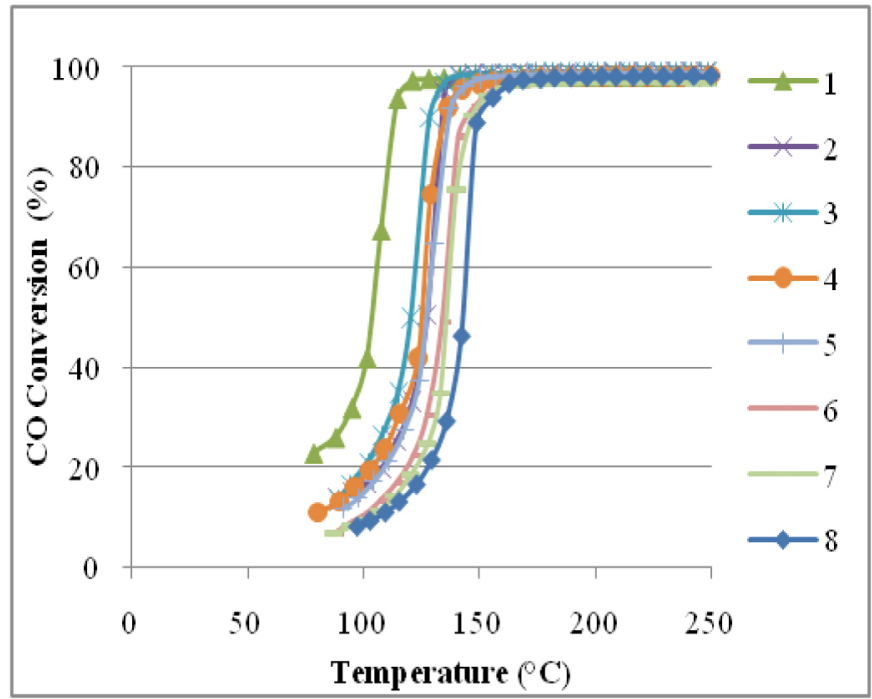

Figure 4. CO Light-Off 1 Conversion Curves Corresponding to the Various Stages of Sample 1's Degreening Process

The conversion curves in Figure 4 clearly show the shift upwards in light-off temperature as the sample was subjected to increasing time in the oven. In addition to the higher lightoff temperature the early conversion of $\mathrm{CO}$ is another notable point. In Test 1 upon injection of the reactant gases (at a temperature of $80^{\circ} \mathrm{C}$ ) the conversion immediately reaches $20 \%$ and as the sample was subjected to repeated stints in the oven this early conversion consistently reduces. Both the trend of increasing light-off temperature and the reduction in high early conversion are indicative of a decline in the sample's activity due to the loss of active surface area during the de-greening phase. The early conversion exhibited by these curves is a characteristic also observed during the pretreatment experiments which are detailed later in this study. It is important to re-iterate that each of these $\mathrm{CO}$ light-off tests were preceded by treatments in $\mathrm{H}_{2}$ and $\mathrm{O}_{2}$. Figure 5 also illustrates the trend of increasing light-off temperature through the de-greening process; however it is less dramatic than that portrayed in Figure 4. The curves in Figure 5 are taken from the second of the two consecutive temperature ramps. At this stage in the light-off test the catalyst sample had been subjected to the reactant gases for one light-off temperature ramp, the cool down period to $80^{\circ} \mathrm{C}$ and the stabilisation at $80^{\circ} \mathrm{C}$ for 10 minutes and so the effect of the pre-treatment strategy is no longer a factor as in the curves represented in Figure 4. As a result there is no 'early conversion' and these curves may be viewed as more representative of the 'normal' activity of this catalyst formulation. The respective light-off temperatures $\left(\mathrm{T}_{50}\right)$ of each curve can be found in Table 3 as well as in a further representation found in Figure 6 . 


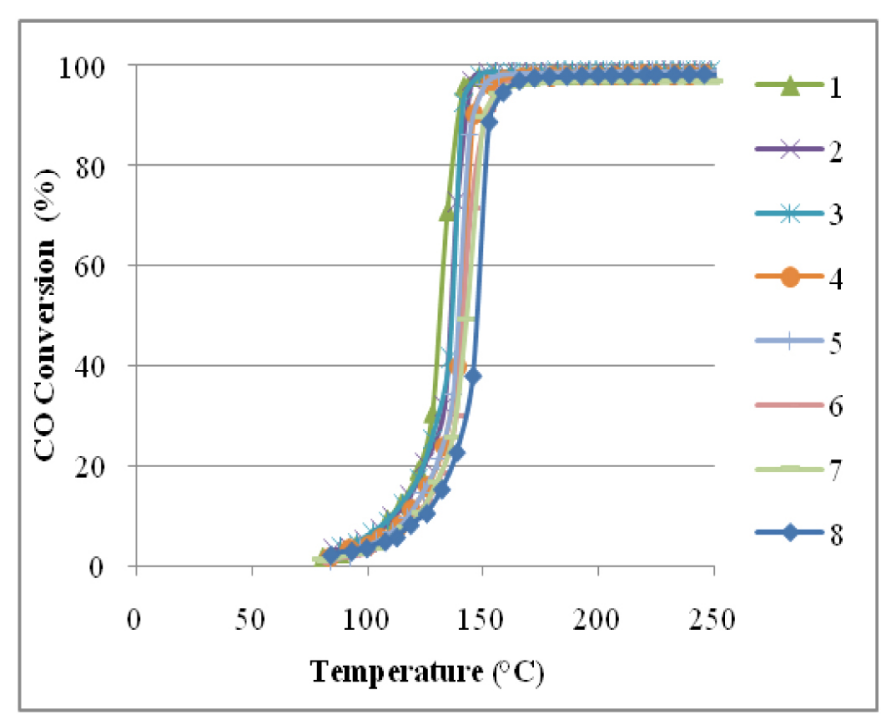

Figure 5. CO Light-Off 2 Conversion Curves Corresponding to the Various Stages of Sample 1's Degreening Process

Table 3. Test Number and Respective Light-Off Temperatures for each Test

\begin{tabular}{|l|c|c|}
\hline $\begin{array}{c}\text { Test Number and } \\
\text { Cumulative Time in Oven }\end{array}$ & $\begin{array}{c}\text { Light-Off } \\
\mathbf{1} \text { Temp } \\
\left({ }^{\circ} \mathbf{C}\right)\end{array}$ & $\begin{array}{c}\text { Light-Off } \\
\text { 2 Temp } \\
\left({ }^{\circ} \mathbf{C}\right)\end{array}$ \\
\hline 1 - Green & 111.5 & 133.5 \\
\hline 2 - Green & 127.0 & 135.0 \\
\hline $3-4 \mathrm{hrs} 600^{\circ} \mathrm{C}$ & 120.5 & 137.0 \\
\hline $4-5 \mathrm{hrs} 600^{\circ} \mathrm{C}$ & 125.5 & 139.5 \\
\hline $5-8 \mathrm{hrs} 600^{\circ} \mathrm{C}$ & 129.5 & 140.0 \\
\hline $6-8 \mathrm{hrs} 600^{\circ} \mathrm{C}+1 \mathrm{hr} 750^{\circ} \mathrm{C}$ & 133.5 & 142.0 \\
\hline $7-8 \mathrm{hrs} 600^{\circ} \mathrm{C}+3 \mathrm{hrs} 750^{\circ} \mathrm{C}$ & 138.0 & 143.0 \\
\hline $8-8 \mathrm{hrs} 600^{\circ} \mathrm{C}+8 \mathrm{hrs} 750^{\circ} \mathrm{C}$ & 142.0 & 147.0 \\
\hline
\end{tabular}

Table 3 and Figure 6 demonstrate the trend of increasing light-off temperature as the sample is de-greened and the trend of an earlier light-off temperature for light-off 1 in each test. However, the difference in the light-off temperatures between ramps 1 and 2 within each test decreases steadily as the sample is de-greened. One discrepancy in this trend can be seen in Test 2 where the light-off 1 temperature was $127^{\circ} \mathrm{C}, 6.5^{\circ} \mathrm{C}$ greater than the subsequent Test 3 where the sample had been placed in the oven for $4 \mathrm{hrs}$ at $600^{\circ} \mathrm{C}$. However, the second light-off temperatures in Tests 1 and 2 are within $1.5^{\circ} \mathrm{C}$ of one other at $133.5^{\circ} \mathrm{C}$ and $135^{\circ} \mathrm{C}$ respectively. The second light-off in Test 3 showed a temperature increase of just $2^{\circ} \mathrm{C}$ to $137^{\circ} \mathrm{C}$ compared to that found in Test 2 despite the time spent in the oven. The sample was de-greened for a further $1 \mathrm{hr}$ at $600^{\circ} \mathrm{C}$ then a further $4 \mathrm{hrs}$ at $600^{\circ} \mathrm{C}$ giving an accumulated total of $8 \mathrm{hrs}$ at $600^{\circ} \mathrm{C}$ in the oven, at this point the sample had shown an increase in light-off temperature for light-off 1 of $18^{\circ} \mathrm{C}$ and light-off 2 of $6.5^{\circ} \mathrm{C}$ compared to Test 1 . Tests 4 and 5, in which the sample had between de-greened for 5 and $8 \mathrm{hrs}$ respectively at $600^{\circ} \mathrm{C}$, showed a further increase of $4^{\circ} \mathrm{C}$ for light-off 1 and $0.5^{\circ} \mathrm{C}$ for light-off 2 . As a result of the declining difference in light-off 2 temperature between Tests 4 and 5 the decision was made to increase the oven temperature to $750^{\circ} \mathrm{C}$ to observe any further effects on the sample's performance caused by a higher temperature. Tests 6,7 and 8 represent the further de-greening at $750^{\circ} \mathrm{C}$ for cumulative totals of 1,4 and $8 \mathrm{hrs}$ respectively. The trend of increasing light-off temperature continued through each of these tests. However, the temperatures observed for light-off 1 in each of the tests saw some convergence towards the temperatures observed on the second light-off, indicating that the surface had become less affected by the pre-treatment in $\mathrm{H}_{2}$ and $\mathrm{O}_{2}$. Following $1 \mathrm{hr}$ at $750^{\circ} \mathrm{C}$ Test 6 showed a $4^{\circ} \mathrm{C}$ increase for light-off 1 compared to Test 5 and a $2^{\circ} \mathrm{C}$ increase for light-off 2 over Test 5 . Test 7 showed a further increase of $4.5^{\circ} \mathrm{C}$ and $1{ }^{\circ} \mathrm{C}$ for the first and second light-offs respectively. Test 8 revealed an increase of $4^{\circ} \mathrm{C}$ for both light-off 1 and 2 . This is notable as light-off 1 had previously experienced a greater increase in temperature than light-off 2 through all of the previous stages. At this point a CO light-off test was performed to observe the behaviour of the sample without the injection of the reactant gases after a warm up temperature ramp in $\mathrm{N}_{2}$ only i.e $\mathrm{CO}$ and $\mathrm{O}_{2}$ were present during the warm-up temperature ramp. The S-curves from this test are shown in Figure 7.

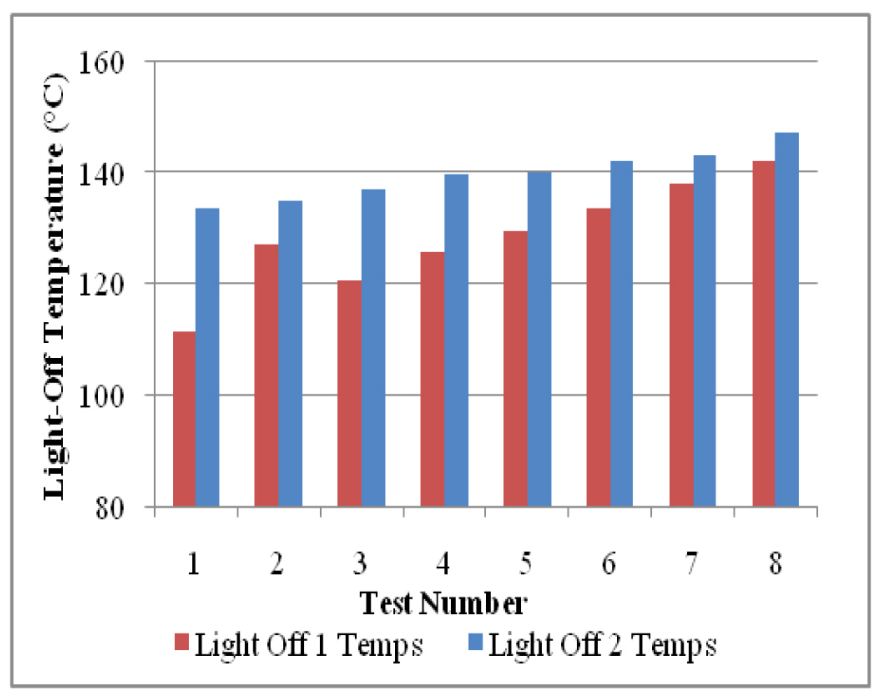

Figure 6. Comparison of Light-Off Temperatures 1 and 2 from each respective stage of De-greening on Sample 1 


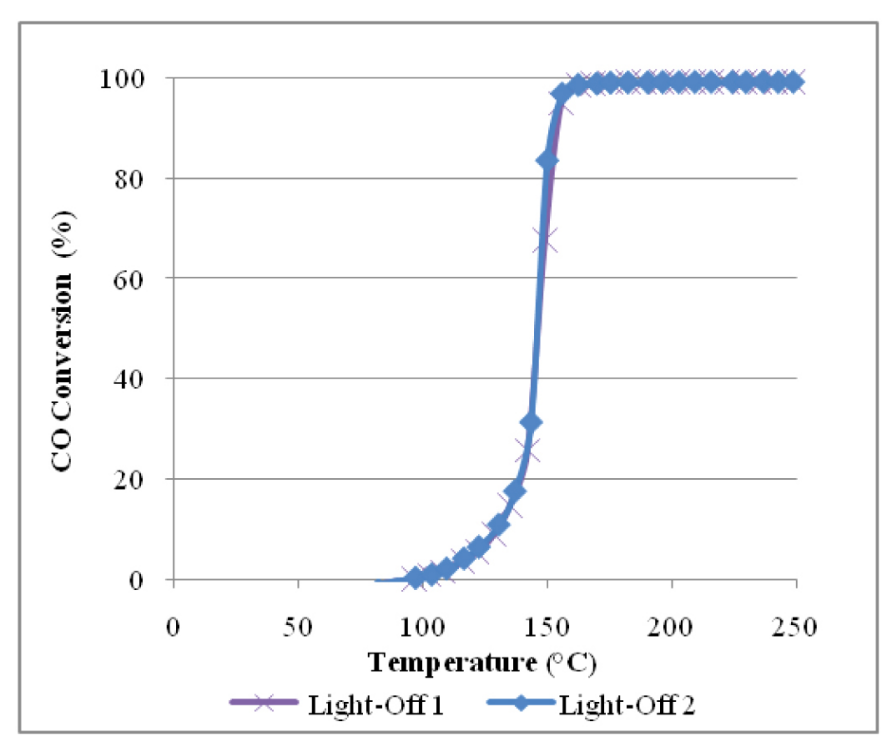

Figure 7. Light-Off Curves using Sample 1 with Full Gas Mixture from Test Start

The light-off temperatures for the test shown in Figure 7 were $147.5^{\circ} \mathrm{C}$ and $146.5^{\circ} \mathrm{C}$ for light-offs 1 and 2 respectively. These temperatures are concurrent with that from the second light-off in Test 8 which had a $\mathrm{T}_{50}$ of $147^{\circ} \mathrm{C}$. Following this test the decision was taken to subject a completely green sample (Sample 2) to a period of $8 \mathrm{hrs}$ at $750^{\circ} \mathrm{C}$ in the oven and subsequently test it under the same protocol as used for Tests 1-8 to observe whether or not it exhibited similar lightoff characteristics to Sample 1. The S-curves obtained from the test on Sample 2 following its $8 \mathrm{hrs}$ at $750^{\circ} \mathrm{C}$ in the oven plus pre-treatments are shown Figure 8 .

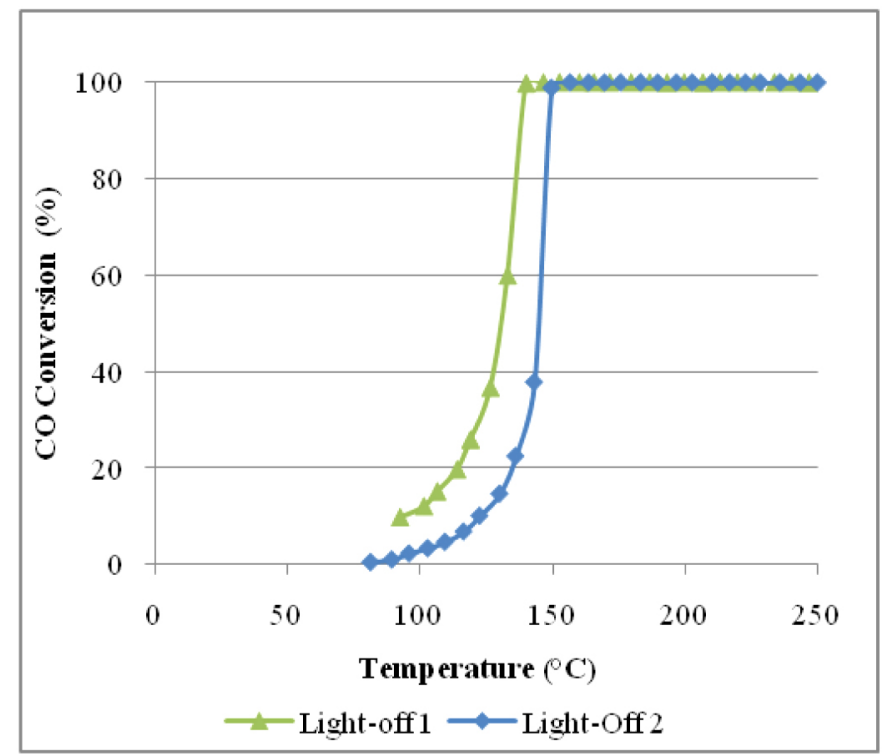

Figure 8. Light-Offs 1 and 2 on Sample 2 following 8hrs at $750^{\circ} \mathrm{C}$ in the Oven
The light-off temperatures were $130^{\circ} \mathrm{C}$ and $145.5^{\circ} \mathrm{C}$ for lightoff 1 and 2 respectively. Although the light-off 1 temperature is concurrent with that seen from Sample 1 in Test 5 (lightoff 1 after $8 \mathrm{hrs}$ de-greening at $600^{\circ} \mathrm{C}$ ) the second light-off is within $1.5^{\circ} \mathrm{C}$ of Test 8 where Sample 1 had also been degreened at $750^{\circ} \mathrm{C}$ for $8 \mathrm{hrs}$. This indicates that Sample 2 had reached a similar surface stability to that of Sample 1 despite the repeated testing to which Sample 1 had been subjected. This proves that Sample 1 had reached a stable surface state as the extensive testing and repeated temperature ramps to $600^{\circ} \mathrm{C}$ during the $\mathrm{H}_{2}$ reduction treatments would have most certainly caused further sintering of the surface. To further compare the activities of Samples 1 and 2, Sample 2 was tested with no pre-treatment using a $\mathrm{CO}$ light-off test with $\mathrm{CO}$ and $\mathrm{O}_{2}$ present during the warm-up ramp thereby replicating the same test procedure performed on Sample 1 represented by Figure 7. The main purpose of this was to demonstrate the performance during a typical light-off test; light-off 1 had a $\mathrm{T}_{50}$ of $145.5^{\circ} \mathrm{C}$ and light-off 2 had a $\mathrm{T}_{50}$ of $146^{\circ} \mathrm{C}$. These temperatures are very repeatable with those from Sample 1 under the same conditions from Figure 7 indicating that $8 \mathrm{hrs}$ in the oven at $750^{\circ} \mathrm{C}$ is sufficient for obtaining repeatable results due to stabilisation of the catalyst surface. Further to the previous tests, a final investigation was performed where Sample 1 was placed in the oven at $800^{\circ} \mathrm{C}$ for a period of 8 consecutive hours and subsequently tested using a CO light-off. The motivation for this test was to ascertain the effect of the slightly higher oven temperature of $800^{\circ} \mathrm{C}$ which may be considered as a transition into the temperature region associated with catalyst ageing and to assess the consequence of this on catalyst performance. The subsequent CO light-off test (conducted as a normal light-off with no pre-treatment) yielded $\mathrm{T}_{50}$ temperatures of $154.5^{\circ} \mathrm{C}$ and $155.5^{\circ} \mathrm{C}$ for light-offs 1 and 2 respectively. The consequence of increasing the de-greening temperature to $800^{\circ} \mathrm{C}$ caused a temperature shift of $8.5^{\circ} \mathrm{C}$ for light-off 1 and $9^{\circ} \mathrm{C}$ for light-off 2 . These temperature shifts are significant compared to those observed previously through the degreening processes. Although the sample may be regarded as being stable at this point it is apparent that the active phase has been more greatly impacted by the higher de-greening temperature than previously observed. Additionally, as $750^{\circ} \mathrm{C}$ is a higher temperature than that to which the sample would be subjected during laboratory testing it was concluded that $750^{\circ} \mathrm{C}$ was a sufficiently high temperature for de-greening as no further detrimental thermal effect would be induced during testing.

\section{PRE-TREATMENT STUDY}

The pre-treatment study test strategies included three separate treatment approaches designed to allow observation of the effect of reducing, oxidising and inert atmospheres on catalytic behaviour and to address the possible requirement to treat a catalyst sample prior to testing to ensure repeatable results. The first procedure for the reduced treatment 
involved subjecting the sample to the same reduction treatment as used for the de-greening tests, $3 \% \mathrm{H}_{2}$ ( $\mathrm{SV}=$ $25,000 \mathrm{~h}^{-1}$ ) with a temperature ramp up to $400^{\circ} \mathrm{C}$ where the temperature was held constant for 10 minutes followed by a further temperature increase to $500^{\circ} \mathrm{C}[\underline{13}][\underline{16}]$. Due to mass flow controller limitations, to achieve a concentration of $3 \%$ $\mathrm{H}_{2}$ the space velocity of this treatment was reduced to 25,000 $\mathrm{h}^{-1}$ as a result a temperature hold at $400^{\circ} \mathrm{C}$ was incorporated to increase the total volume of the reducing mixture through the sample. This treatment was followed by a CO light-off test. The second pre-treatment involved an identical reduction to that detailed previously followed by oxidation of the sample in $5 \% \mathrm{O}_{2}\left(50,000 \mathrm{~h}^{-1}\right)$ where the temperature was increased to $192^{\circ} \mathrm{C}$ and held there for 30 minutes before a cool down [12-13]. This was followed by a CO light-off test. The third and final pre-treatment strategy used $\mathrm{N}_{2}(\mathrm{SV}=$ $50,000 \mathrm{~h}^{-1}$ ), in this case a $15^{\circ} \mathrm{C} / \mathrm{min}$ temperature ramp up to $600^{\circ} \mathrm{C}$ was used before the sample was subjected to a $\mathrm{CO}$ light-off test. This profile was designed within the limits of the test equipment as $15^{\circ} \mathrm{C} / \mathrm{min}$ was an easily achievable temperature ramp rate and $600^{\circ} \mathrm{C}$ is the recommended upper limit for the integrated furnace. A summary of the treatment specifications can be found in Table 4. For each CO light-off test following the respective pre-treatment strategies the same light-off test procedure was used as detailed previously for the de-greening activity tests in that the warm up ramp was performed in $\mathrm{N}_{2}$ only. This method showed interesting results as the effect of each pre-treatment had on the sample surface was evident particularly on the first light-off temperature ramp.

Table 4. Pre-Treatment Specifications

\begin{tabular}{|c|c|c|c|}
\hline $\begin{array}{c}\text { Treatment } \\
\text { Type }\end{array}$ & $\begin{array}{c}\text { Gas } \\
\text { Composition }\end{array}$ & $\begin{array}{c}\text { Space } \\
\text { Velocity } \\
\left(\mathbf{h}^{-1}\right)\end{array}$ & $\begin{array}{c}\text { Temperature } \\
\text { Profile }\end{array}$ \\
\hline Reduction & $3 \% \mathrm{H}_{2}$ in $\mathrm{N}_{2}$ & 25,000 & $\begin{array}{c}15^{\circ} \mathrm{C} / \mathrm{min} \text { to } \\
400^{\circ} \mathrm{C} \text {, held at } \\
400^{\circ} \mathrm{C} \text { for } \\
10 \mathrm{mins} \text { then } \\
10^{\circ} \mathrm{C} / \mathrm{min} \text { up to } \\
500^{\circ} \mathrm{C}\end{array}$ \\
\hline Oxidation & $5 \% \mathrm{O}_{2}$ in $\mathrm{N}_{2}$ & 50,000 & $\begin{array}{c}192^{\circ} \mathrm{C} \text { for } 30 \\
\text { minutes }\end{array}$ \\
\hline Inert & $\mathrm{N}_{2}$ & 50,000 & $\begin{array}{c}15^{\circ} \mathrm{C} / \mathrm{min} \text { up to } \\
600^{\circ} \mathrm{C}\end{array}$ \\
\hline
\end{tabular}

The pre-treatments were performed on a green sample (Sample 3) and also on the de-greened Sample 1 to highlight any differences between the effect on a green and a stabilised sample.

\section{Hydrogen Reduction Pre-Treatment}

The first pre-treatment strategy tested was a reduction using $3 \% \mathrm{H}_{2}$ in $\mathrm{N}_{2}$. A CO light-off followed the pre-treatment. Figures 9 and 10 show the species observed during the reduction in $\mathrm{H}_{2}$ using the green Sample 3.

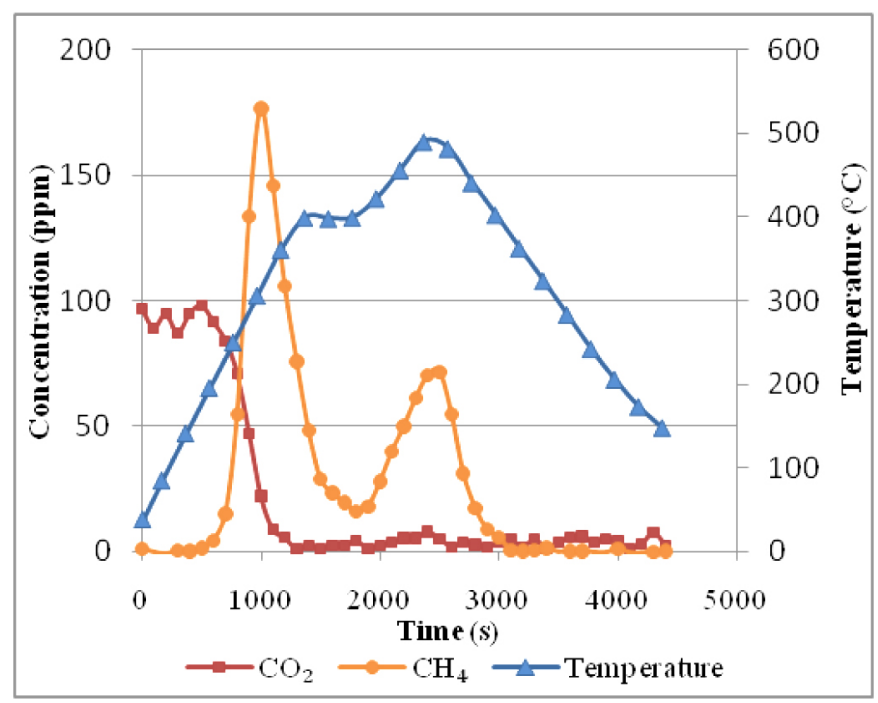

Figure 9. $\mathrm{CO}_{2}$ and $\mathrm{CH}_{4}$ emission during the Reduction of Green Sample 3

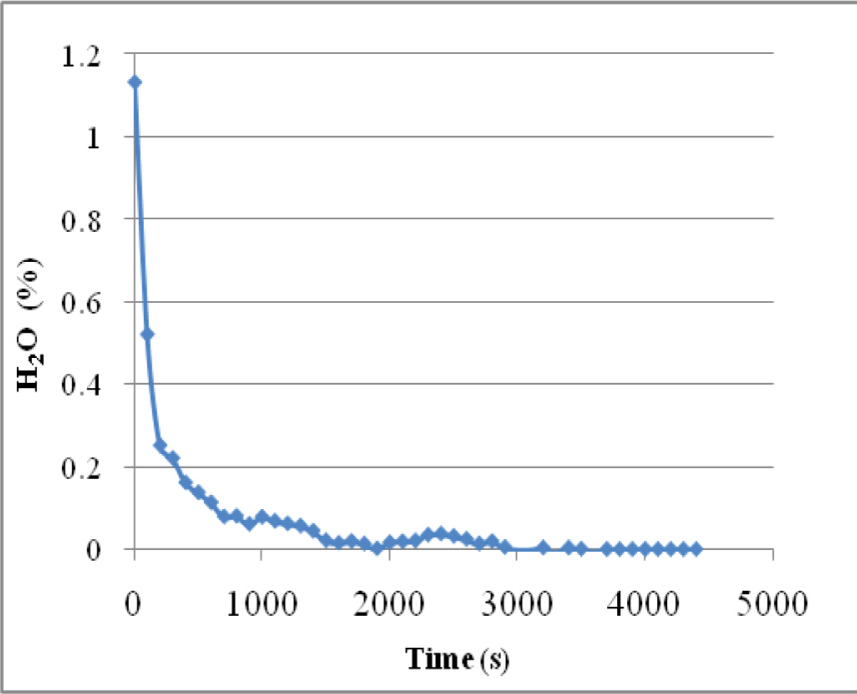

Figure 10. Emission of $\mathrm{H}_{2} \mathrm{O}$ during $\mathrm{H}_{2}$ Reduction of Green Sample 3 
$\underline{\text { Figures } 9}$ and $\underline{10}$ show a significant emission of $\mathrm{CO}_{2}, \mathrm{CH}_{4}$ and $\mathrm{H}_{2} \mathrm{O}$ during the reduction of Sample 3 using $3 \% \mathrm{H}_{2}$. It is important to note that $\mathrm{N}_{2}$ and $\mathrm{H}_{2}$ were the only gases entering the catalyst. Initially, it is clear that $\mathrm{CO}_{2}$ and $\mathrm{H}_{2} \mathrm{O}$ were emitted from the surface of the sample. The presence of water is not unexpected due to oxygen being retained on the surface which would combine with the $\mathrm{H}_{2}$ in the gas stream introduced to the catalyst, however the $\mathrm{CO}_{2}$ must have been emitted directly from the surface of the sample. As the $\mathrm{CO}_{2}$ and $\mathrm{H}_{2} \mathrm{O}$ deplete the emission of $\mathrm{CH}_{4}$ becomes prominent peaking at around $170 \mathrm{ppm}$. During the temperature hold at $400^{\circ} \mathrm{C}$ the level of methane emitted dropped but increased during the temperature ramp to $500^{\circ} \mathrm{C}$ before finally depleting entirely on the cool down ramp. It appears that once the $\mathrm{O}_{2}$ on the sample surface had depleted during the first 1000s of the reduction the $\mathrm{H}_{2}$ in the feed gas then reacted with the remaining carbon atoms on the sample surface forming methane. The results of the CO light-off which followed this reduction are shown in Figure 11.

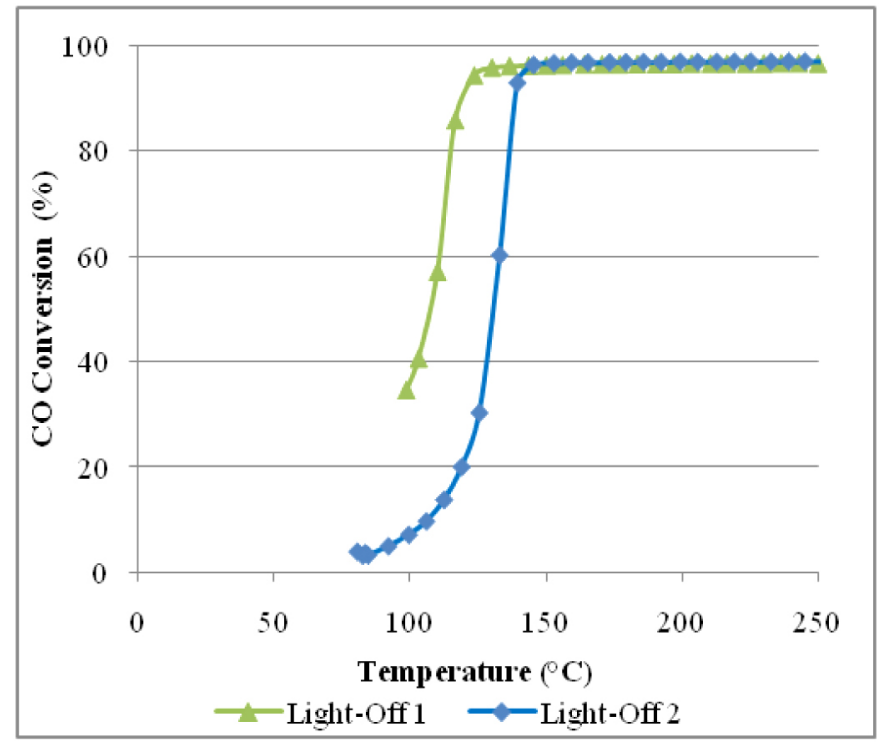

Figure 11. CO Light-Off Curves following $\mathrm{H}_{2}$ Reduction on Green Sample 3

Light-off 1 had a $\mathrm{T}_{50}$ temperature of $108.5^{\circ} \mathrm{C}$ while light-off 2 had a $\mathrm{T}_{50}$ of $131^{\circ} \mathrm{C}$. This pre-reduced light-off test produced the highest 'early conversion' of any test upon injection of the reactant gases with conversion not dropping below $30 \%$ for light-off 1 . The sample also converted $3 \%$ of the $\mathrm{CO}$ feed gas during the temperature stabilisation ramp between light-offs 1 and 2 at a temperature of around $80^{\circ} \mathrm{C}$. This very high activity can be attributed to the fact that the sample is green and therefore in its most active state. However, the early conversion displayed in light-off 1 must be due to the reduced state of the sample surface. The $\mathrm{H}_{2}$ pretreatment had stripped the surface of $\mathrm{O}_{2}$ and upon injection of
$\mathrm{CO}$ and $\mathrm{O}_{2}$ in the feed stream following the warm up in $\mathrm{N}_{2}$ a spike of $\mathrm{H}_{2} \mathrm{O}$ was observed. This is most likely due to hydroxyl ions remaining on the surface and subsequently reacting with the newly present $\mathrm{O}_{2}$ causing a significant exotherm of around $40^{\circ} \mathrm{C}$ to be observed downstream of the sample [12]. As a result of this increase in the sample bed temperature some $\mathrm{CO}$ and $\mathrm{O}_{2}$ would have had sufficient energy to react hence causing the early conversion exhibited. This would have further been facilitated by the reduction treatment having cleaned the surface by removing carbon atoms in the form of methane as shown in Figure 10; resulting in significantly more available active sites for absorption and subsequent reaction. As the test continued through to maximum conversion, cool down and stabilisation the conversion dropped as expected. By this stage the surface would have returned to a more typical state having adsorbed $\mathrm{CO}$ and $\mathrm{O}_{2}$ resulting in a more 'normal' S-curve shape for light-off 2.

Sample 1, which had been previously used in the de-greening study, was also tested to assess the effect of $\mathrm{H}_{2}$ pre-treatment and to understand how significant the factor of Sample 3 being green had on the results shown above. The species observed during the reduction on Sample 2 are shown in $\underline{\text { Figures } 12}$ and $\underline{13}$.

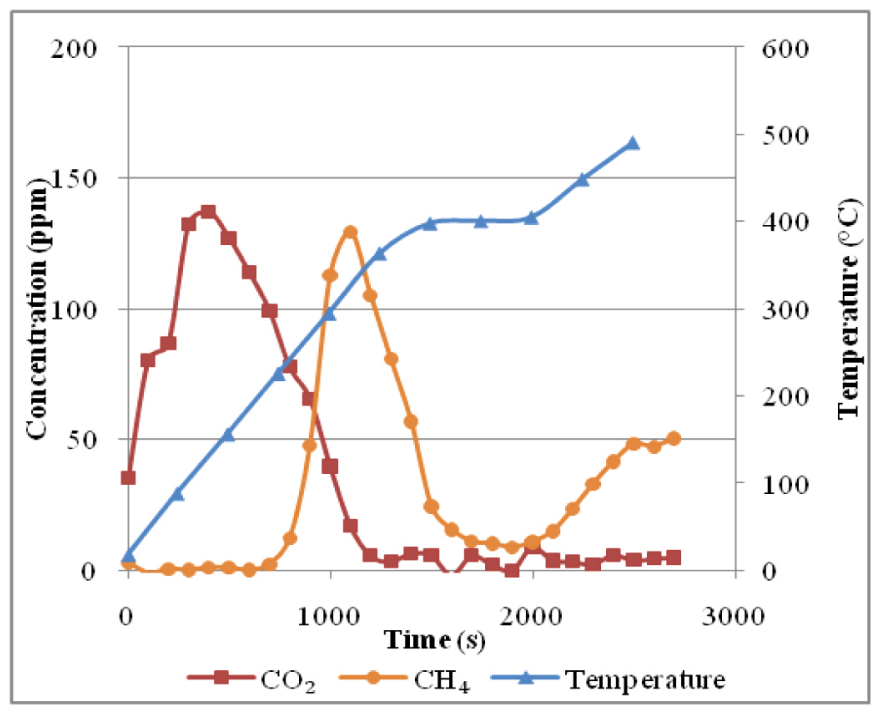

Figure 12. Gas Species emitted from De-greened Sample 1 during $\mathrm{H}_{2}$ Reduction Pre-Treatment 


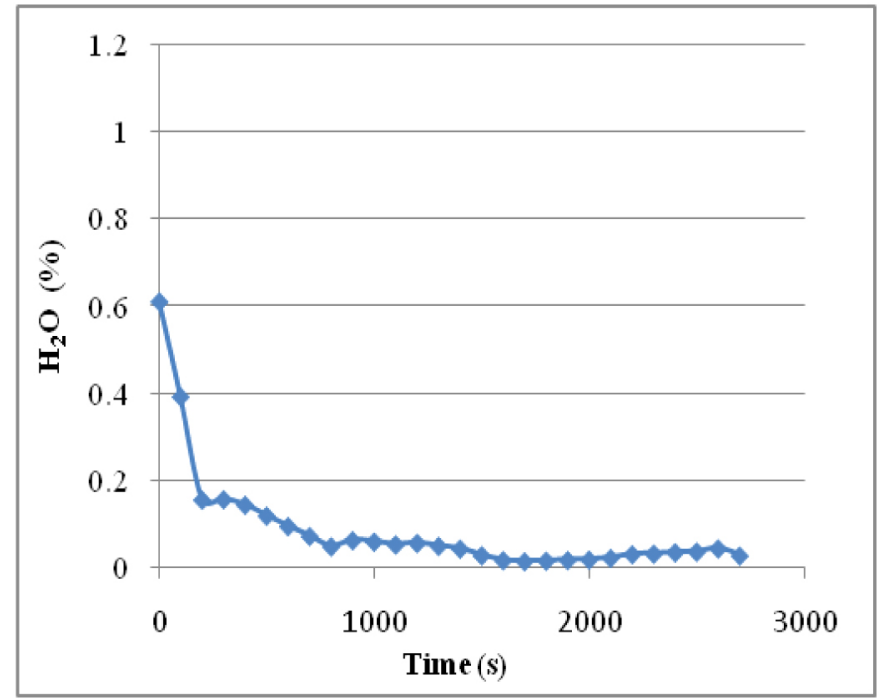

Figure 13. $\mathrm{H}_{2} \mathrm{O}$ emitted during Reduction of Sample 1

Once again $\mathrm{CO}_{2}$ and $\mathrm{CH}_{4}$ were emitted from the sample, however, in comparison with the green sample more $\mathrm{CO}_{2}$ was observed in this case while the level of $\mathrm{CH}_{4}$ is similar. Figure $\underline{13}$ shows a decrease in water emission during this reduction, $0.6 \%$ peak compared to $1.15 \%$ from Sample 3 in Figure 10 . This may be due to the higher level of $\mathrm{CO}_{2}$ emitted indicating that more of the surface was occupied with $\mathrm{CO}_{2}$ than $\mathrm{O}_{2}$. Following this reduction a $\mathrm{CO}$ light-off was performed, the $\mathrm{S}$ curves are shown in Figure 14.

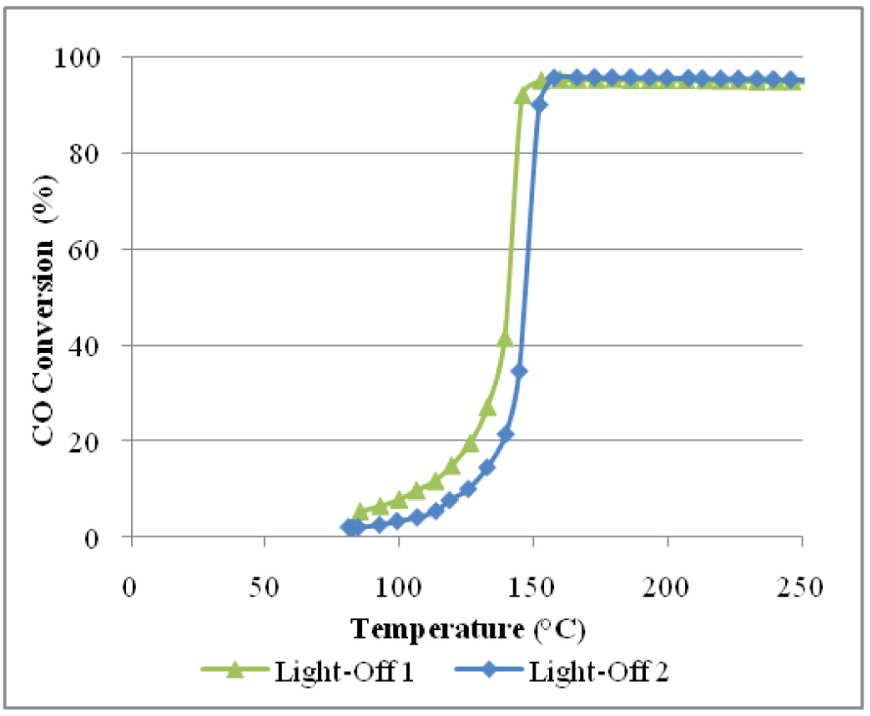

Figure 14. Reduced Light-Off S-Curves from Sample 1
The light-off temperatures for this test were $140.5^{\circ} \mathrm{C}$ and $148^{\circ} \mathrm{C}$ for light-offs 1 and 2 respectively. In comparison with Sample 3 this is an increase of $31.5^{\circ} \mathrm{C}$ for light-off land $17^{\circ} \mathrm{C}$ for light-off 2 . The early conversion observed in light-off 1 was $5 \%$ compared with $30 \%$ on the green sample. This illustrates that the de-greening procedure to which Sample 1 had been subjected had a significant effect on the surface as expected. However, the chemically reduced surface did decrease the temperature of light-off 1 by $8^{\circ} \mathrm{C}$ from that off light-off 2.

\section{Oxidation Pre-Treatment}

The oxidation pre-treatment followed a similar procedure to that used in the reduction in that the samples were reduced in $\mathrm{H}_{2}$ then oxidised using $5 \% \mathrm{O}_{2}$. Having observed the large amount of $\mathrm{CO}_{2}$ and $\mathrm{CH}_{4}$ emitted during the reduction treatment the decision was taken to reduce the sample before oxidation to ensure that results representative of a fully oxidised surface were portrayed. Once again Sample 3 was used to illustrate the effect on a green sample.

The reduction phase exhibited similar trends to those shown previously and so has not been presented here. Figure 15 shows the oxidation sweep of the catalyst which followed the reduction. This was performed at a constant temperature of $192^{\circ} \mathrm{C}$

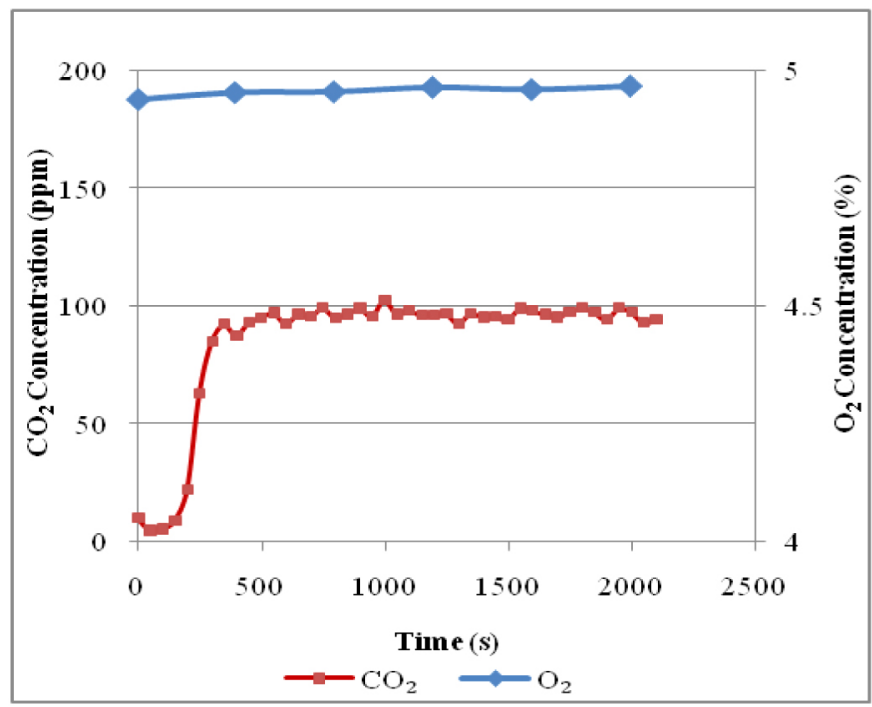

Figure 15. Oxidation of Sample 3 in 5\% O2 Pre CO Light-Off 
Figure 15 shows an interesting characteristic of no $\mathrm{CO}_{2}$ being observed for the first 200 s then a consistent amount was omitted throughout the remainder of the test. The $\mathrm{CO}_{2}$ originated from the compressed air which is used for the oxidation; this trend suggests that the catalyst adsorbed the $\mathrm{CO}_{2}$ during the first 200s. A control test was performed with no catalyst present which showed a continuous amount of $\mathrm{CO}_{2}$ throughout the test therefore proving that in the first 200s of the test shown in Figure 15, the $\mathrm{CO}_{2}$ must have been adsorbed on the catalyst surface. Following the oxidation a $\mathrm{CO}$ light-off was performed, the S-curves from which are shown in Figure 16.

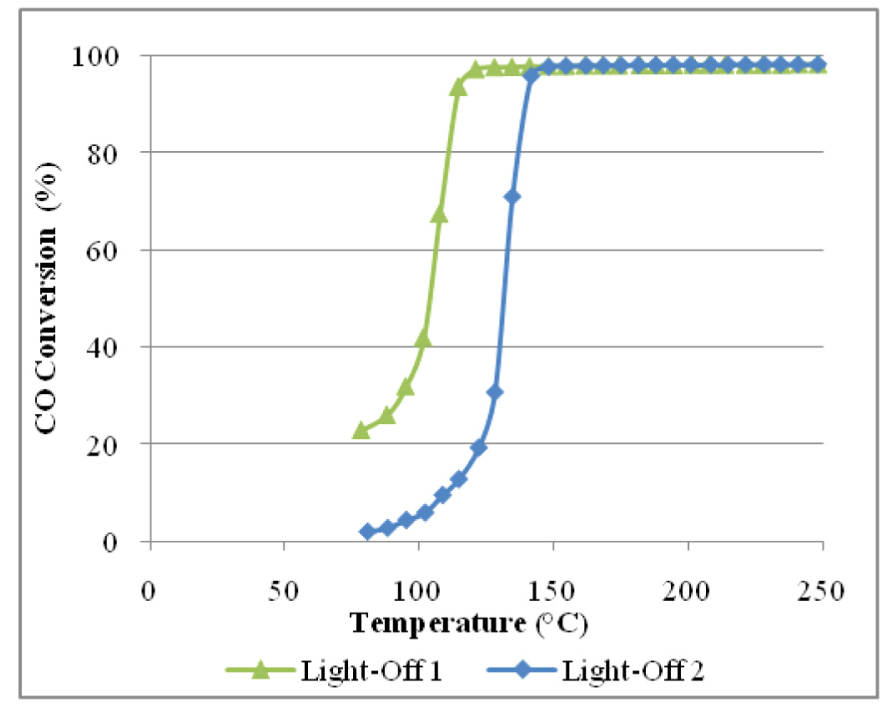

Figure 16. CO Light-Off on Sample 3 following Oxidation using $5 \% \mathrm{O}_{2}$

Light-off 1 had a $\mathrm{T}_{50}$ of $111.5^{\circ} \mathrm{C}$ which is $3^{\circ} \mathrm{C}$ higher than the hydrogen reduced light-off on the same sample. Light-off 2 had a $\mathrm{T}_{50}$ of $133.5^{\circ} \mathrm{C}, 2.5^{\circ} \mathrm{C}$ higher than the hydrogen reduced light-off 2 temperature on this sample. The early conversion seen on light-off 1's curve was just over $20 \%$ compared to the $30 \%$ observed on the reduced test. However, unlike the reduced test there was no spike of water observed upon injection of the reactant gases following the warm up in $\mathrm{N}_{2}$. This further indicates that $\mathrm{H}_{2}$ atoms remain on the surface following a reduction using hydrogen resulting in the emission of water when the reactant gases are injected.

As in the hydrogen pre-treatment study, this oxidised lightoff test was replicated using the de-greened Sample 1. The oxidation of the sample following a reduction is shown in Figure 17 and the S-curves from the CO light-off are shown in Figure 18.

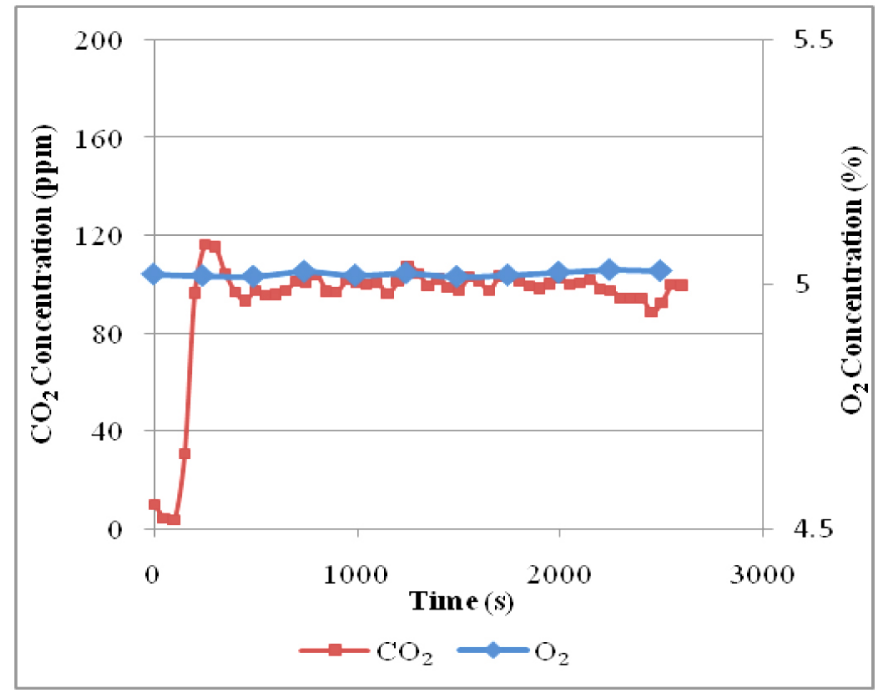

Figure 17. $\mathrm{CO}_{2}$ and $\mathrm{O}_{2}$ Profiles during Oxidation of Sample 1

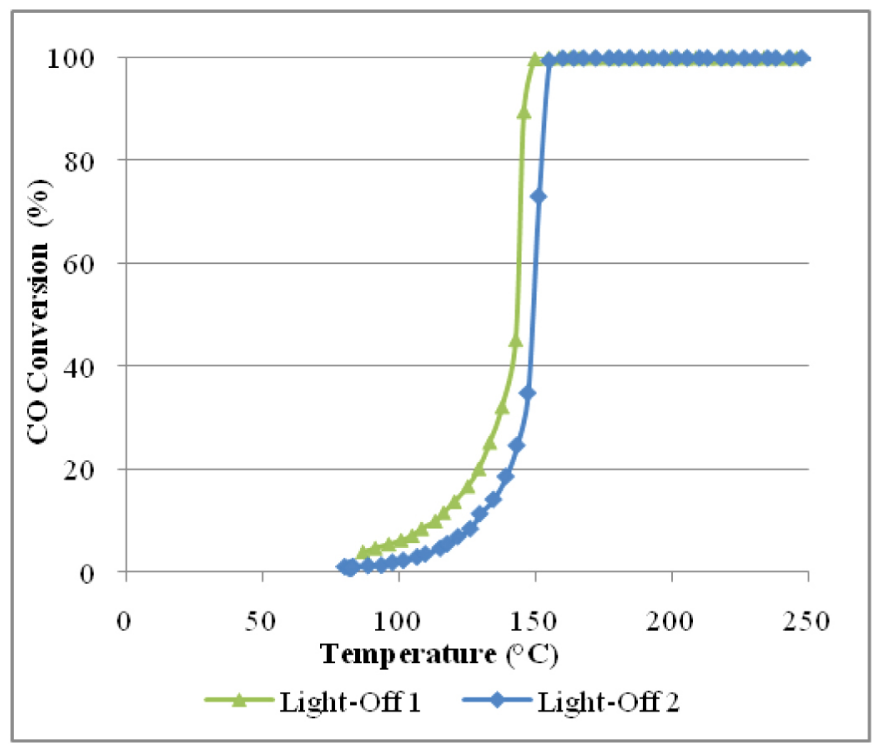

Figure 18. S-Curves from Oxidised CO Light-Off on Sample 1

Figure 17 shows a similar trend to that seen previously from the green sample in Figure 15 indicating little difference between the green and de-greened samples during the oxidation treatment. The S-curves reveal a significant reduction in activity particularly on light-off 1 which was also observed in the hydrogen reduced light-off tests between Samples 1 and 3. Light-off 1 in Figure 18 had a $\mathrm{T}_{50}$ of $143^{\circ} \mathrm{C}$ which is $32.5^{\circ} \mathrm{C}$ higher than the green sample while light-off 2 had a $\mathrm{T}_{50}$ of $150^{\circ} \mathrm{C}$ which was the highest light-off temperature observed from this sample. This may be explained by the Pd having been oxidised by the oxygen pretreatment and the lean mixture used for the light-off tests. This combination could cause the activity to be slightly 
diminished due to high oxygen coverage on the surface. In comparison with the reduction pre-treatment in this case light-off 1 was $2.5^{\circ} \mathrm{C}$ later and light-off 2 was $2^{\circ} \mathrm{C}$ later than seen on the reduced, de-greened sample.

\section{Nitrogen Pre-Treatment}

The procedure used for the $\mathrm{N}_{2}$ pre-treatment used a temperature ramp of $15^{\circ} \mathrm{C} / \mathrm{min}$ up to $600^{\circ} \mathrm{C}$. The $\mathrm{N}_{2}$ treatment on the green sample again showed emission of $\mathrm{CO}_{2}$ which depleted immediately after the heating ramp was complete as shown in Figure 19. Following the $\mathrm{N}_{2}$ treatment a CO light-off was performed, the S-curves from this test can be seen in Figure 20.

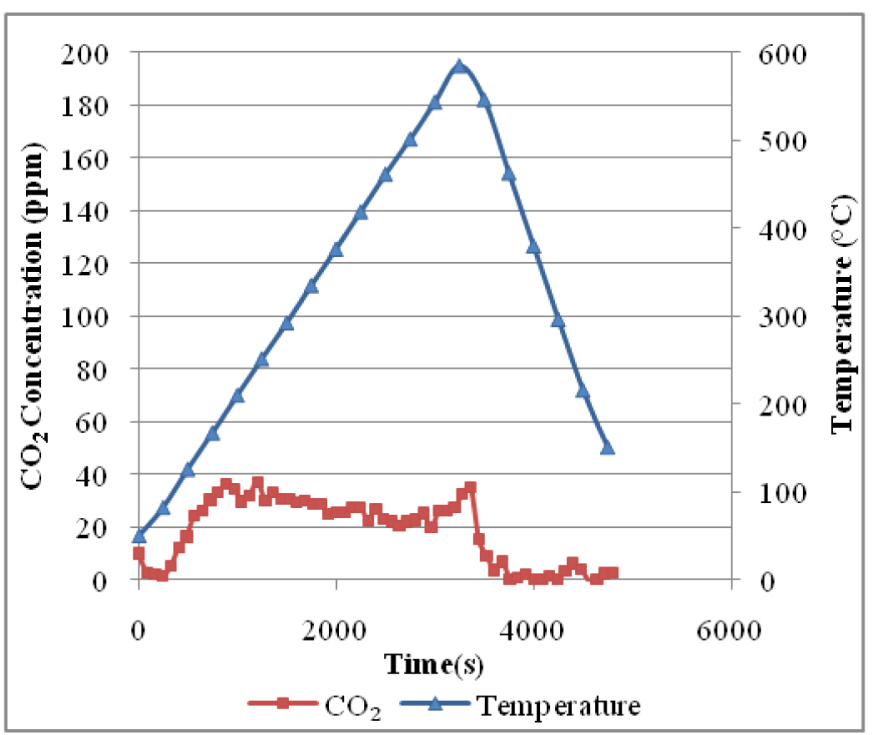

Figure 19. $\mathrm{CO}_{2}$ Emission during $\mathrm{N}_{2}$ Treatment from Green Sample

The light-off temperature for ramp 1 was $119^{\circ} \mathrm{C}$ and light-off 2 had a temperature of $140^{\circ} \mathrm{C}$; both of these temperatures are the highest observed in comparison with the reduced and oxidised treatments suggesting that the $\mathrm{N}_{2}$ treatment had less of a promoting effect on the subsequent light-off test.

The de-greened catalyst (Sample 1) was then treated using the same procedure and tested with a CO light-off. The emissions during the $\mathrm{N}_{2}$ treatment and the subsequent lightoff curves can be seen in Figures 21 and 22 respectively.

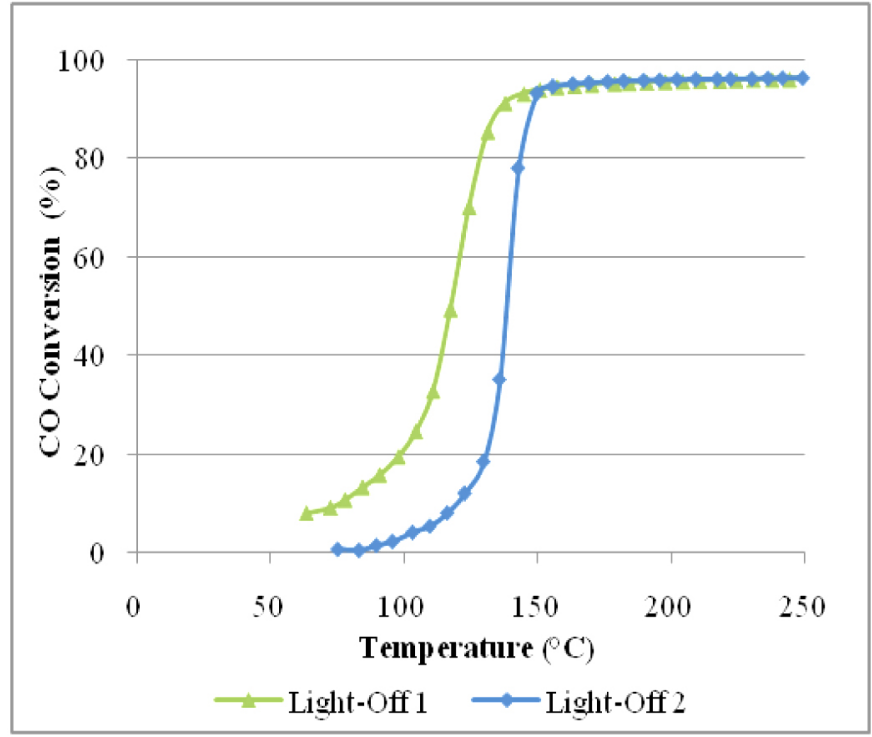

Figure 20. S-Curves from a CO Light-Off following an $\mathrm{N}_{2}$ Pre-Treatment on Green Sample 3

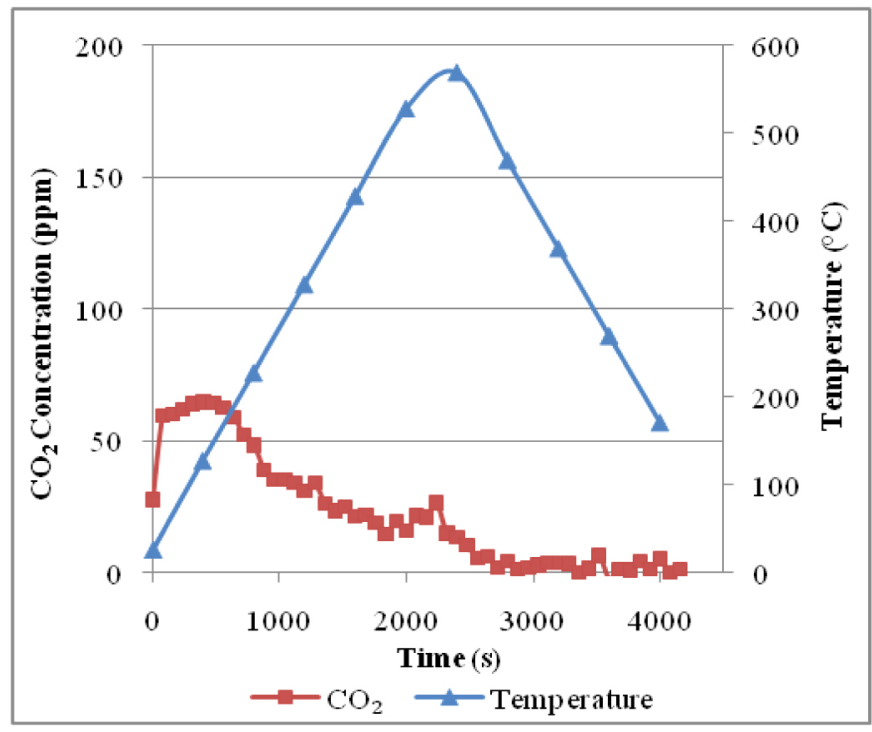

Figure 21. $\mathrm{CO}_{2}$ Emission during $\mathrm{N}_{2}$ Pre-Treatment on Sample 1 


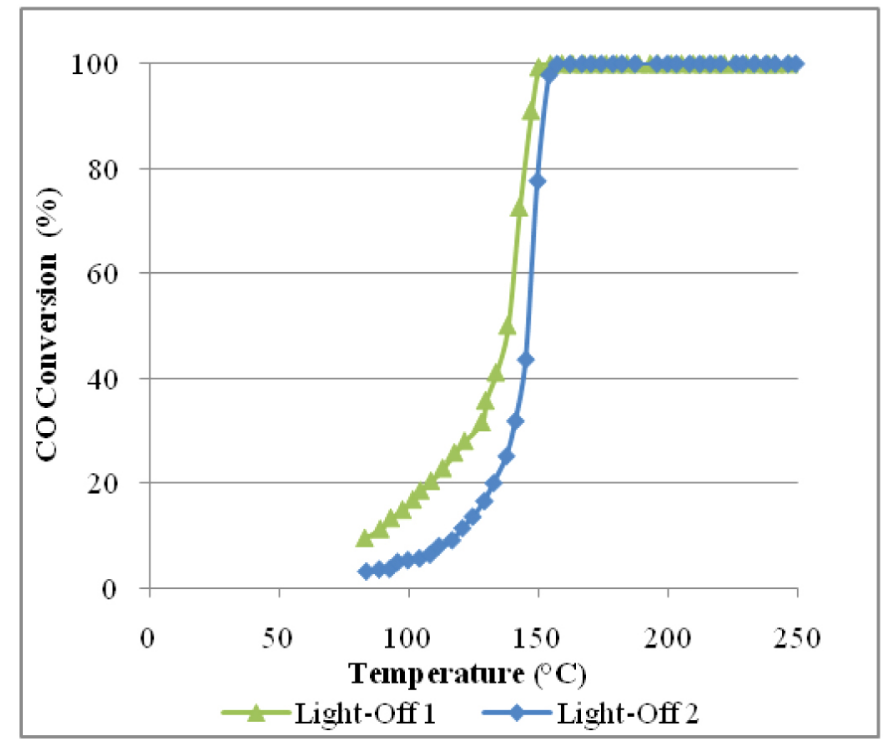

Figure 22. Light-Off Curves from Sample 1 following $\mathrm{N}_{2}$ Pre-Treatment

Figure 21 demonstrates the emission of $\mathrm{CO}_{2}$ during the $\mathrm{N}_{2}$ treatment from de-greened Sample 1 as previously observed from the green sample in Figure 19. Following the treatment the CO light-off produced the S-curves seen in Figure 22. The light-off temperatures in this case were $138^{\circ} \mathrm{C}$ and $146.5^{\circ} \mathrm{C}$ for light-offs 1 and 2 respectively. Figures 23 and 24 show a comparison of the light-off temperatures for the green and de-greened samples following each respective pretreatment.

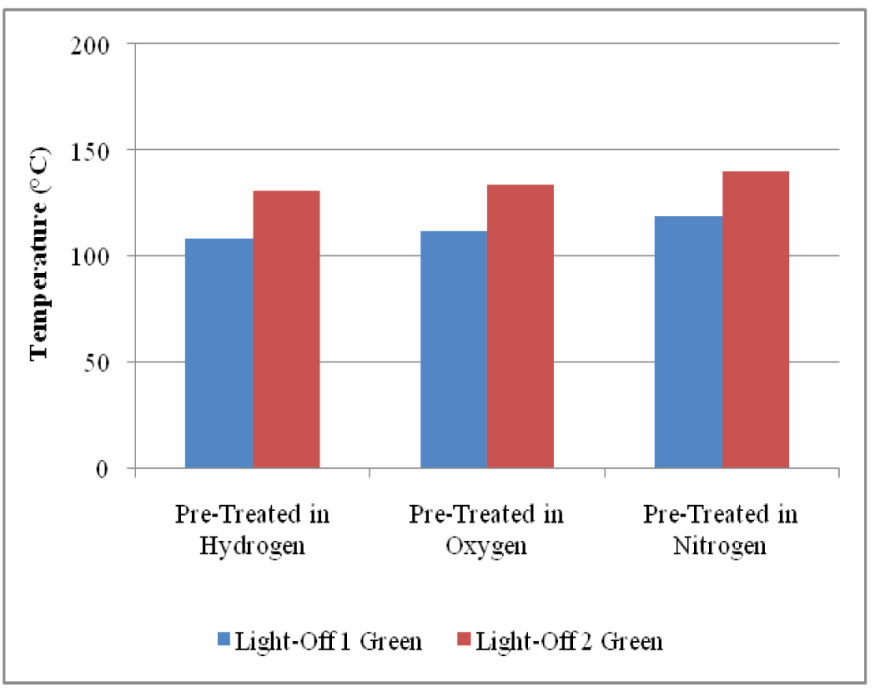

Figure 23. Pre-Treated CO Light-Off Temperatures on Green Sample 3

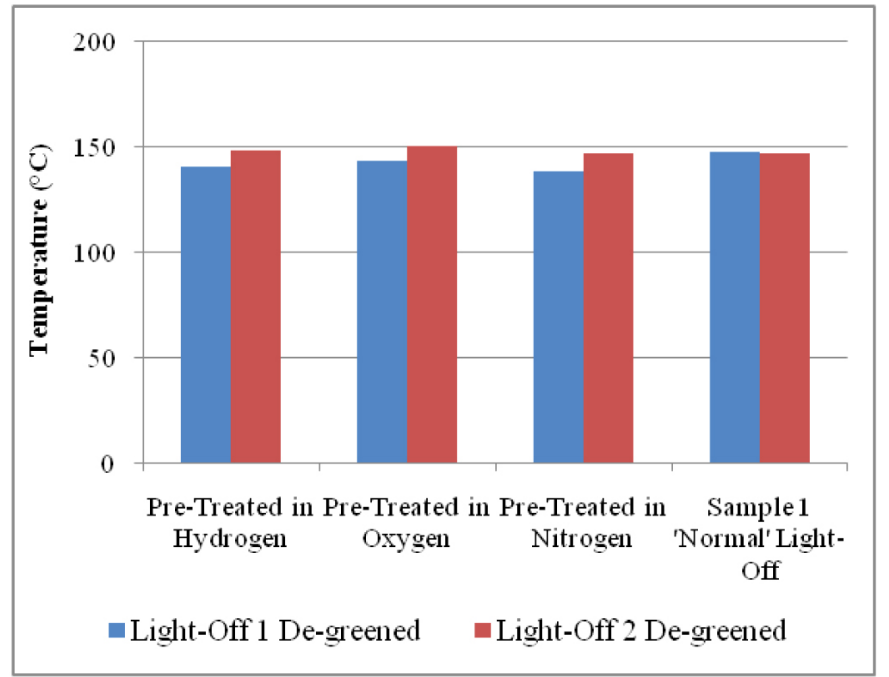

Figure 24. Pre-Treated CO Light-Off Temperatures on De-Greened Sample 1

Figure 23 shows a trend of increasing light-off temperature from light-off 1 to light-off 2 in each of the respective treatments; this can be attributed to the pre-treatment having altered the surface of the sample causing low temperature activity for light-off 1 . The hydrogen treatment gave the lowest light-off 1 temperature followed by the oxidation treatment while the nitrogen treatment gave the highest results for both light-offs on the green sample. Figure 24 shows the temperatures obtained from the de-greened Sample 1. In addition to the results from the various pre-treatment tests also included is the result from the 'normal' light-off test performed on Sample 1 previously detailed in Figure 7 where Sample 1 had light-off temperatures of $147.5^{\circ} \mathrm{C}$ and $146.5^{\circ}$ for light-offs 1 and 2 respectively. This acts as a representation of typical light-off temperatures expected from the sample. Comparing the results of the pre-treatment tests in Figures 23 and $\underline{24}$ the difference between light-offs 1 and 2 has reduced dramatically on the de-greened sample. This indicates that all of the pre-treatments have the greatest effect when used on a green sample due to the greater surface area of precious metal available. The pre-treatments on Sample 1 saw the highest temperature from the pre-oxidised test on light-off 2; this may be a side effect of high oxygen coverage on the surface leading to diminished available active sites for the incoming $\mathrm{CO}$ reactant gas. The pre-treatment in nitrogen gave a light-off temperature of $146.5^{\circ} \mathrm{C}$ making it the most consistent with the 'normal' light-off.

However, it is necessary to note that all three pre-treatments yielded similar light-off 2 temperatures and so if the reactant gases $\left(\mathrm{CO}\right.$ and $\left.\mathrm{O}_{2}\right)$ were present from the beginning of the light-off tests it is highly likely that all the light-off temperatures would be very similar. Overall, it is thought that the nitrogen treatment is the most economical and logistically viable solution and would neither chemically reduce nor 
oxidise the surface to a state unrepresentative of its typical operation.

\section{CONCLUSIONS}

As a result of the study described the following procedures for preparing catalyst samples prior to testing for the purpose of measuring reaction kinetics are recommended:

1. In order to remove the influence of the rapid change in surface area during the early stages of catalyst sample's test life de-greening is required. A temperature of $600^{\circ} \mathrm{C}$ is often used for de-greening, however this temperature proved insufficient for this catalyst. It was concluded that the sample used in this study required a temperature of $750^{\circ} \mathrm{C}$ for a period of 8 hours in air to achieve sufficient stability. The use of a temperature greater than $750^{\circ} \mathrm{C}$ would be considered as aging the sample.

2. The pre-treatment study further underlined the need for adequate de-greening of a test sample prior to the commencement of its test life. The effect of each of the respective treatments using $\mathrm{H}_{2}, \mathrm{O}_{2}$ and $\mathrm{N}_{2}$ was most prominent on the green sample while the de-greened sample was much less susceptible to variation in light-off temperature following the treatments. In particular the reduction treatment using hydrogen resulted in high activity from the green sample. The oxidation treatment showed an interesting trend of $\mathrm{CO}_{2}$ adsorption which would also have affected the surface chemistry and the subsequent activity. The most inexpensive and logistically viable solution to ensure that the surface of the PM is in an identical condition prior to each test was found to be pre-treatment in nitrogen by using a temperature profile of $15^{\circ} \mathrm{C} / \mathrm{min}$ up to a temperature of $600^{\circ} \mathrm{C}$.

\section{REFERENCES}

1. Kaspar, J., Fornasiero, P., Hickey, N., “Automotive catalytic converters: current status and some perspectives," Catalysis Today 77, p. 419-449, 2002, doi: $\underline{10.1016 /}$ S0920-5861(02)00384-X.

2. Olsson, L., Andersson, B., "Kinetic modelling in automotive catalysis," Topics in Catalysis 28, p. 89-98, 2004, doi: 10.1023/B:TOCA.0000024337.50617.8e

3. Samenfink, W., Albrodt, H., Frank, M., Gesk, M. et al., "Strategies to Reduce HC-Emissions During the Cold Starting of a Port Fuel Injected Gasoline Engine," SAE Technical Paper 2003-01-0627, 2003, doi:

10.4271/2003-01-0627.

4. Lafyatis, D.S., Ansell, G.P., Bennett, S.C., Frost, J.C., Millington, P.J., Rajaram, R.R., Walker, A.P, Ballinger, T.H., "Ambient temperature light-off for automobile emission control," Applied Catalysis B: Envir. 18, p. 123-135, 1998, doi: 10.1016/S0926-3373(98)00032-0.

5. Kubo, S., Yamamoto, M., Kizaki, Y., Yamazaki, S. et al., "Speciated Hydrocarbon Emissions of SI Engine during Cold
Start and Warm-up," SAE Technical Paper 932706, 1993, doi: $10.4271 / 932706$.

6. Kelly, K., Bailey, B., Coburn, T., Clark, W. et al., "Federal Test Procedure Emissions Test Results from Ethanol Variable-Fuel Vehicle Chevrolet Luminas," SAE Technical Paper 961092, 1996, doi: $\underline{10.4271 / 961092}$.

7. Benson, J., Koehl, W., Burns, V., Hochhauser, A. et al., "Emissions with E85 and Gasolines in Flexible/Variable Fuel Vehicles - The Auto/Oil Air Quality Improvement Research Program," SAE Technical Paper 952508, 1995, doi: $10.4271 / 952508$.

8. Lupescu, J., Chanko, T., Richert, J., and DeVries, J., "Treatment of Vehicle Emissions from the Combustion of E85 and Gasoline with Catalyzed Hydrocarbon Traps," SAE Int. J. Fuels Lubr. 2(1):485-496, 2009, doi: 10.4271/2009-01-1080.

9. Voltz, S.E., Morgan, C.R., Liederman, D., Jacob, S.M., "Kinetic Study of Carbon Monoxide and Propylene Oxidation on Platinum Catalysts," Ind.Eng. Chem. Prod. Res. Develop. 12(4), p. 294-301, 1973, doi: 10.1021/i360048a006.

10. Torcrona, A., Skoglundh, M., Thormahlen, P., Fridell, E., Jobson, E., "Low temperature catalytic activity of cobalt oxide and ceria promoted Pt and Pd: -influence of pretreatment and gas composition," Applied Catalysis 14, p. 131-146, 1997, doi:10.1016/S0167-2991(06)80965-1.

11. Yee, A., Morrison, S.J., Idriss, H., "A Study of the Reactions of Ethanol on $\mathrm{CeO}_{2}$ and $\mathrm{Pd} / \mathrm{CeO}_{2}$ by Steady State

Reactions, Temperature Programmed Desorption, and In Situ FT-IR," Journal of Catalysis 186, p. 279-295, 1999, doi: $\underline{10.1006 / \text { jcat.1999.2563. }}$.

12. Holmgren, A., Azarnoush, F., Fridell, E., "Influence of pre-treatment on low temperature activity of $\mathrm{Pt} /$ ceria," Applied Catalysis B: Envir. 22, p. 49-61, 1999, doi:10.1016/ S0926-3373(99)00033-8.

13. Burch, R., Millington, P.J., Walker, A.P., "Mechanism of the selective reduction of nitrogen monoxide on platinum based catalysts in the presence of excess oxygen," Applied Catalysis B: Envir. 4, p. 65-94, 1994.

14. Bernal, S., Botana, F.J., Calvino, J.J., Cauqui, M.A., Cifredo, G.A., Jobacho, A., Pintado, J.M., RodriguezIzquierdo, J.M., "Microstructural and Chemical Properties of Ceria-Supported Rhodium Catalysts Reduced at 773K," Journal of Physical Chemistry 97, p. 4118-4123, 1993, doi: 10.1021/j100118a031.

15. Bernal, S., Calvino, J.J, Cifredo, G.A., Gatica, J.M., Perez Omil, J.A., Pintado, J.M., "Hydrogen Chemisorption on Ceria: Influence of the Oxide Surface Area and Degree of Reduction," Journal of Catalysis 89, p.3499-3505, 1993, doi: 10.1039/FT9938903499.

16. Golunski, S.E., Hatcher, H.A., Rajaram, R.R., Truex, T.J., "Origins of low-temperature three-way activity in $\mathrm{Pt} /$ 
$\mathrm{CeO}_{2}$," Applied Catalysis B: Envir. 5, p. 367-376, 1994, doi: 10.1016/0926-3373(94)00057-3.

\section{CONTACT INFORMATION}

Claire McAtee

School of Mechanical and Aerospace Engineering

Queen's University Belfast Ashby Building

Stranmillis Rd, Belfast, BT9 5AH

cmcatee03@qub.ac.uk

Dr Geoffrey McCullough

School of Mechanical and Aerospace Engineering

Queen's University Belfast Ashby Building

Stranmillis Rd, Belfast, BT9 5AH

g.mccullough@qub.ac.uk

\section{DEFINITIONS/ABBREVIATIONS}

BOC

British Oxygen Company

CO

Carbon monoxide

$\mathrm{CO}_{2}$

Carbon dioxide

$\mathrm{CH}_{4}$

Methane

$\mathbf{H}_{2}$

Hydrogen

$\mathrm{H}_{2} \mathrm{O}$

Water

HCs

Hydrocarbons

LMFC

Liquid Mass Flow Controller

MFC

Mass Flow Controller

$\mathbf{N}_{2}$

Nitrogen
$\mathrm{NO}_{\mathbf{x}}$

Oxides of nitrogen

$\mathrm{O}_{2}$

Oxygen

Pd

Palladium

PM

Precious Metal

ppm

Parts per million

Pt

Platinum

Rh

Rhodium

SIGU

Simulated Gas Generator

$\mathrm{SO}_{2}$

Sulphur dioxide

$\mathbf{T}_{50}$

Light-off temperature

TWC

Three-way catalyst 
The Engineering Meetings Board has approved this paper for publication. It has successfully completed SAE's peer review process under the supervision of the session organizer. This process requires a minimum of three (3) reviews by industry experts.

All rights reserved. No part of this publication may be reproduced, stored in a retrieval system, or transmitted, in any form or by any means, electronic, mechanical, photocopying, recording, or otherwise, without the prior written permission of SAE.

ISSN 0148-7191
Positions and opinions advanced in this paper are those of the author(s) and not necessarily those of SAE. The author is solely responsible for the content of the paper.

SAE Customer Service:

Tel: 877-606-7323 (inside USA and Canada)

Tel: 724-776-4970 (outside USA)

Fax: 724-776-0790

Email: CustomerService@sae.org

SAE Web Address: http://www.sae.org

Printed in USA 